\title{
Scalable PbS Quantum Dot Solar Cell Production by Blade Coating from Stable Inks
}

\author{
Nataliia Sukharevska, Dmytro Bederak, Vincent M. Goossens, Jamo Momand, Herman Duim, \\ Dmitry N. Dirin, Maksym V. Kovalenko, Bart J. Kooi, and Maria A. Loi*
}

Cite This: ACS Appl. Mater. Interfaces 2021, 13, 5195-5207

Read Online

ABSTRACT: The recent development of phase transfer ligand exchange methods for $\mathrm{PbS}$ quantum dots (QD) has enhanced the performance of quantum dots solar cells and greatly simplified the complexity of film deposition. However, the dispersions of $\mathrm{PbS}$ QDs (inks) used for film fabrication often suffer from colloidal instability, which hinders large-scale solar cell production. In addition, the wasteful spin-coating method is still the main technique for the deposition of QD layer in solar cells. Here, we report a strategy for scalable solar cell fabrication from highly stable $\mathrm{PbS} \mathrm{QD}$ inks. By dispersing $\mathrm{PbS} \mathrm{QDs}$ capped with $\mathrm{CH}_{3} \mathrm{NH}_{3} \mathrm{PbI}_{3}$ in 2,6-difluoropyridine (DFP), we obtained inks that are colloidally stable for more than 3 months. Furthermore, we

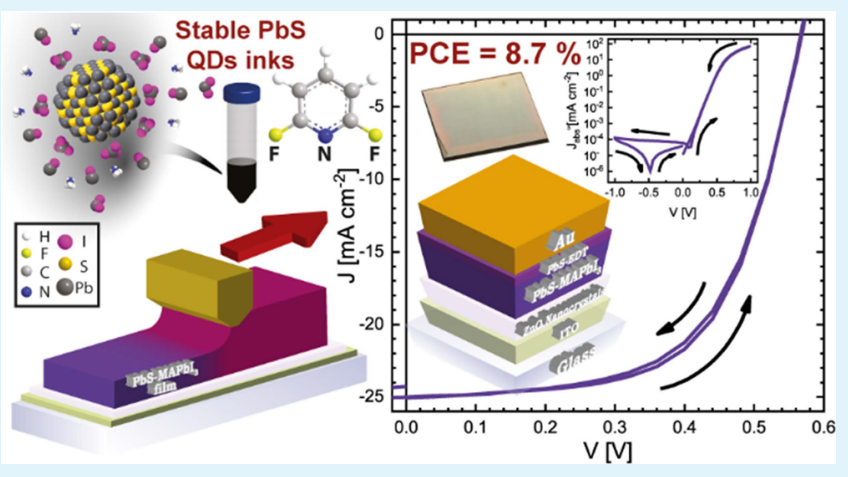
demonstrated that DFP yields stable dispersions even of large diameter $\mathrm{PbS}$ QDs, which are of great practical relevance owing to the extended coverage of the near-infrared region. The optimization of blade-coating deposition of DFP-based inks enabled the fabrication of PbS QD solar cells with power conversion efficiencies of up to $8.7 \%$. It is important to underline that this performance is commensurate with the devices made by spin coating of inks with the same ligands. A good shelf life-time of these inks manifests itself in the comparatively high photovoltaic efficiency of $5.8 \%$ obtained with inks stored for more than 120 days.

KEYWORDS: quantum dots, lead sulfide, solar cells, blade coating, colloidal stability, scalable fabrication, perovskite ligands, phase transfer ligand exchange

\section{INTRODUCTION}

$\mathrm{PbS}$ colloidal quantum dots (QDs) have received significant attention as promising building blocks for optoelectronic devices due to their size-dependent band gap and tunability of electronic properties by means of surface chemistry and solution-processability. ${ }^{1,2}$ In the past years, QDs have been applied for the fabrication of field-effect transistors, ${ }^{3-5}$ lightemitting diodes, ${ }^{6,7}$ light-emitting field-effect transistors, ${ }^{8}$ inverters, ${ }^{9}$ photodetectors, ${ }^{10-12}$ and photovoltaic devices. $^{11,13-17}$ In the context of photovoltaic applications, PbS QDs are appealing for their direct optical band gap and thus high absorption coefficient, ${ }^{18}$ the potential of multiple exciton generation, ${ }^{19}$ and the possibility for absorption of the infrared part of the spectrum. ${ }^{20,21}$ Advances in PbS QD synthesis, ${ }^{22}$ device architecture engineering, ${ }^{23-26}$ and QD surface passivation strategies ${ }^{27,28}$ brought the current power conversion efficiency (PCE) value to above $13 \%{ }^{13}$ and enabled impressive air stability of non-encapsulated devices. ${ }^{2,29}$

Compared with the fabrication of other electronic devices, in solar cell manufacturing, it is critical to produce uniform, thick, crack-free films with homogeneous material distribution throughout the entire thickness and area. ${ }^{30}$ For PbS QDs, the ideal theoretical film thickness value for maximal light harvesting is around $1 \mu \mathrm{m} .{ }^{31,32}$ However, in research examples of PbS QD photovoltaic devices, the optimal thickness is just $100-400 \mathrm{~nm}$ due to the presence of QD surface traps and energetic disorder in the solid, there is a limited charge carrier diffusion length. For many years, one of the biggest complications of $\mathrm{PbS} \mathrm{QD}$ solar cell fabrication was the deposition of thick and defect-free films. A tedious and material wasteful layer by layer $(\mathrm{LbL})$ spin-coating technique has been used to achieve a thicknesses of 100-200 nm in majority of published $\mathrm{PbS} \mathrm{QD}$ solar cells..$^{23,25,26,29,33}$ In this method, 10-15 cycles of alternating steps, including PbS QD deposition, solid-state ligand exchange, and several washing steps. Solid-state ligand exchange also does not allow good surface passivation of QDs since the efficiency of the ligand-

Received: October 10, 2020

Accepted: January 8, 2021

Published: January 20, 2021 
exchange reaction depends on the penetration depth of the ligand solution into the film. Unreplaced native ligands, dangling bonds, and residual ligand-exchange reaction products not washed away can all potentially become sources of carrier recombination, which usually results in low operating voltages and poor carrier mobilities. Due to the residual native long-chain organic ligands, QD films can often be loosely packed with consequent negative effects for carrier transport. Problems related to incomplete ligand exchange in solid-state reactions can be partly overcome by additional ligand exchange steps, where part of the native ligands is replaced before solidstate ligand exchange, ${ }^{34}$ making the device fabrication process even more complex. Besides that, during the in situ solid-state ligand exchange reaction, volume contraction of the film occurs and the stress can lead to the emergence of micro- and macrocracks and film delamination, especially during the last steps when attempting to obtain thicker films. ${ }^{31}$ LbL ligand exchange also implies the extended exposure of the film to solvents, which may dissolve parts of the devices and be destructive for the active layer itself.

Of immense importance for the QD photovoltaics field was the recent development of the phase-transfer (solution-phase) ligand exchange. ${ }^{16,31,35-37}$ In this case, QDs are surrounded by a uniform liquid reaction medium, which allows a complete ligand exchange as well as easy separation of byproducts. An equally important benefit of this method is the possibility to deposit, in a single step, a thick, compact, and crack-free QD film from solution (inks), where QDs are already surrounded by the desired ligands, saving a considerable amount of materials and time. This method, however, requires a judicious choice of the solvents (for the ligand exchange itself and for storage and deposition) and the kind and amounts of ligands. In the past years, a variety of ligands were employed for preparing $\mathrm{QD}$ inks. Among them, the most common are methylammonium iodide (MAI), lead halides (mostly $\mathrm{PbI}_{2}$ and $\left.\mathrm{PbBr}_{2}\right)$, other metal halide complexes $\left(\mathrm{MX}_{n}\right)$, hybrid passivation by equimolar mixtures of the MAI and lead halides ( $\mathrm{MAPbX}_{3}$ perovskite precursors), and nonequimolar MAX/ $\mathrm{MX}_{n}$ mixtures, which forms coordination compounds of different stoichiometries compared to perovskites, precursors mixtures, which form other kinds of perovskites $\left(\mathrm{CsPbI}_{3}\right.$, $\mathrm{Cs}_{x} \mathrm{MA}_{y} \mathrm{FA}_{z} \mathrm{PbX}_{3}$, where $\mathrm{FA}$ is the formamidinium cation). ${ }^{10,14-16,36,38,39}$ Some studies argued that the lattice coherence between the ligands crystal structure and $\mathrm{PbS}$ is important for the quality of ligand coating and $\mathrm{QD}$ passivation. ${ }^{10,38}$ Nevertheless, it is still debated in the literature, which ligands are the most suitable for $\mathrm{PbS} \mathrm{QDs}$ for photovoltaic application. Irrespective of the choice of ligands, a common problem for the $\mathrm{PbS} \mathrm{QD}$ inks is their colloidal instability in the most common solvent selected for the deposition, namely, $n$-butylamine (BA). ${ }^{14,27,40} \mathrm{PbS}$ QDs dispersed in BA typically start to agglomerate and precipitate within the first few hours after preparation. BA is selected as a suitable solvent for inks mainly because of its low boiling point $\left(78{ }^{\circ} \mathrm{C}\right)$, which is convenient for spin coating. The amino group in $\mathrm{BA}$ can coordinate to the surface of the as-prepared $\mathrm{PbI}_{3}{ }^{-}$capped $\mathrm{PbS}$ QDs, but BA as a solvent is neither polar enough for efficient electrostatic colloidal stabilization nor bulky enough to enable sufficient steric repulsion of individual QDs.

A few strategies have been proposed to improve the $\mathrm{PbS} \mathrm{QD}$ inks colloidal stability: (i) to use solvents mixture of BA with longer-chain amines (amylamine, and especially hexylamine), ${ }^{14}$ whereby additional steric repulsion of the longer amines helps to improve stabilization; (ii) to add 3-mercaptopropionic acid (MPA), ${ }^{27}$ which improves the stability due to the chemical bonding between MPA and BA; and (iii) to use solvents with a much higher dielectric constant, for example, propylene carbonate (PC), ${ }^{35}$ which increases the stability of the ink due to the better ligands dissociation. The latter, however, leads to new difficulties for the film deposition since the majority of the solvents with high dielectric constants also have a high boiling point (the boiling point of PC is $242{ }^{\circ} \mathrm{C}$ ).

A separate issue in the field is the ligand exchange and colloidal stabilization of larger PbS QDs (diameters $>4 \mathrm{~nm}$ ), which are very interesting for their extended IR absorption. $^{20,21,40,41}$ A stable dispersion of larger diameter PbS nanoparticles is more difficult to obtain since, due to their cuboctahedral shape, they exhibit a greater contribution of the nonpolar (100) facets to the entire surface area, ${ }^{42}$ and the ions, which efficiently stabilize (111) facets, do not attach in the same manner to nonpolar facets. While we were preparing this manuscript, Xia et al. published an interesting way to synthesize $\mathrm{PbS}$ QDs without or with very little contribution of (100) facets. $^{43}$ It could be a very interesting approach especially for larger diameter $\mathrm{PbS} \mathrm{QDs}$, which are often affected by traps due to poor passivation of these facets. Spincoating deposition by itself is not suited for industrial deployment as most of the ink is wasted during the process. Dip coating has also been implemented earlier ${ }^{44}$ for devices fabricated by the LbL technique, but while it helps in lowering the material consumption, it is still very time-consuming in the $\mathrm{LbL}$ approach. There are very few reports on the fabrication of solar cells by spray coating, ${ }^{35}$ but the efficiencies of solar cells fabricated by this method lag far behind the best $\mathrm{PbS} \mathrm{QD}$ devices. Blade coating of the active layer is attractive for its scalability, as is similar to other industrial techniques such as roll-to-roll printing (R2R). While the number of publications reporting $\mathrm{PbS} \mathrm{QD}$ solar cells obtained by blade coating from BA dispersions is very limited, devices perform comparably to the best devices fabricated by multistep spin coating. ${ }^{45,46}$

In our recent publication, ${ }^{47}$ we have demonstrated $\mathrm{PbS} \mathrm{QD}$ inks stability in two different polar solvents, namely, in propylene carbonate and 2,6-difluoropyridine (DFP), with the ink in DFP preserving the electronic properties for over 3 months. DFP is an interesting solvent for QD solar cell fabrication since it is characterized by a high dielectric constant and a relatively low boiling point. Using DFP, in this work, we propose a strategy for the fabrication of $\mathrm{PbS} \mathrm{QD}$ solar cells, which accomplishes both QD inks colloidal stability over more than 120 days and scalable deposition of PbS QD films. PbS QD ink deposition based on DFP is optimized by the bladecoating technique, giving rise to devices of a power conversion efficiency (PCE) of $8.7 \%$, on par with spin-coated devices using the same ligands published earlier $(8.5 \%)^{16}$ and much better than devices fabricated with the same ligands by LbL solid-state processing (4.25\%). ${ }^{33}$ Furthermore, we demonstrated that it is possible to fabricate solar cells with reasonable performance even from inks that were aged for more than 120 days. Importantly, inks made of PbS QDs of bigger sizes (with the first excitonic peak absorption at $1100 \mathrm{~nm}$ ) are also stable in DFP; thus, our strategy can be potentially used for the fabrication of IR absorbers in tandem solar cells and IR detectors. 


\section{RESULTS AND DISCUSSION}

$\mathrm{PbS}$ quantum dots with oleic acid ligands ( $\mathrm{PbS}-\mathrm{OA}$ ) were synthesized using the hot injection method, and phase-transfer ligand exchange was performed as described previously. ${ }^{36,48}$ Briefly, $\mathrm{PbS} \mathrm{QDs}$ in hexane were stirred vigorously with a stoichiometric mixture of lead iodide $\left(\mathrm{PbI}_{2}\right)$ and methylammonium iodide (MAI) in $\mathrm{N}$-methylformamide (NMF) for at least $3 \mathrm{~h}$ (as schematically depicted in Figure 1a). We chose

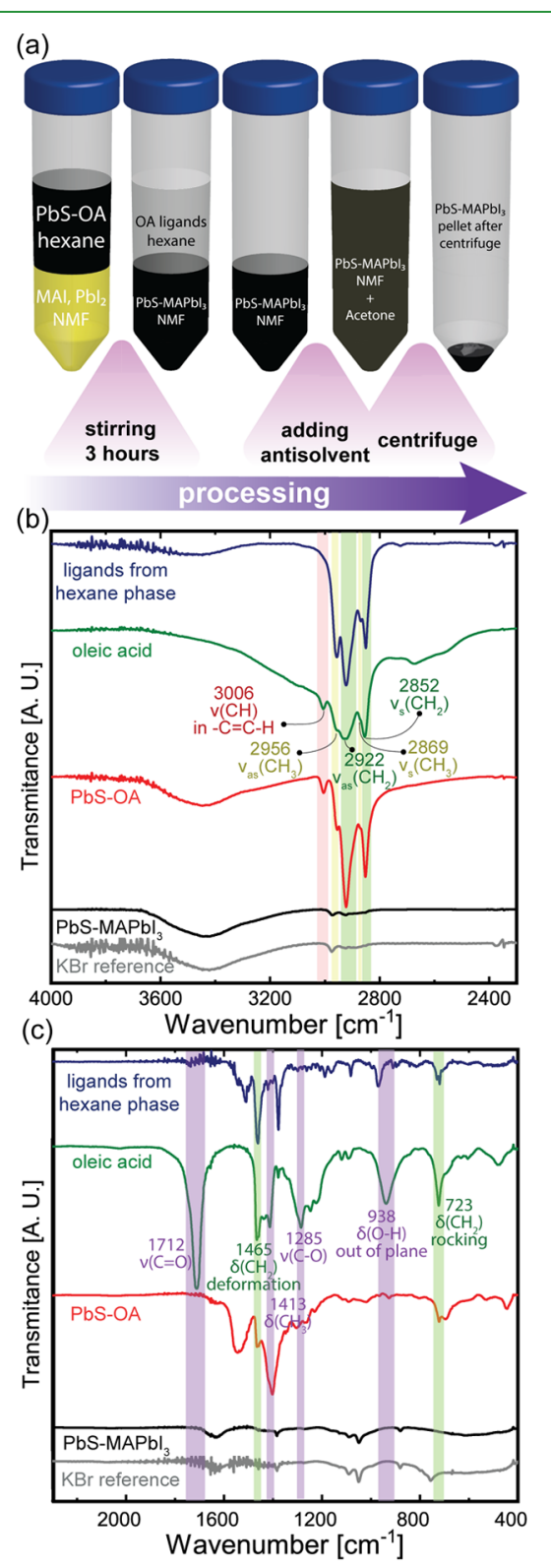

Figure 1. (a) Preparation of the $\mathrm{PbS}-\mathrm{MAPbI}_{3}$ quantum dots inks. FTIR spectra of the $\mathrm{PbS}$ quantum dots before and after ligand exchange, organic phase after ligand exchange, and oleic acid: (b) high energy region and (c) low energy region of the FTIR spectra.

the $\mathrm{MAPbI}_{3}$ precursor as the capping ligand because this formulation was shown to retain an efficient near-infrared PL, indicating a good electronic passivation of the QD surface. ${ }^{36}$ After the ligand exchange, $\mathrm{PbS}$ QDs migrate into NMF, seen as discoloration of the hexane phase. The two phases separate within 1-3 min after ceasing the stirring, and then the hexane phase was discarded. The polar phase was washed three times with hexane to remove the remaining organic ligands. In order to purify the QDs from the excess of the $\mathrm{MAPbI}_{3}$ precursor, the QDs were precipitated by the addition of an antisolvent (acetone). The flocculated QDs were isolated by centrifugation and decantation and redispersed in DFP.

Ligand exchange completeness was verified by FTIR measurements in transmission mode (Figure 1b,c). Signals in the range $2800-3000 \mathrm{~cm}^{-1}$ are assigned to the $\mathrm{C}-\mathrm{H}$ stretching modes. $\mathrm{PbS} \mathrm{QDs}$ with native ligands ( $\mathrm{PbS}-\mathrm{OA}$ ) show five different peaks, the ones at 2956 and $2869 \mathrm{~cm}^{-1}$ are from the asymmetric and symmetric stretching vibrations of the $-\mathrm{CH}_{3}$ group, respectively; the most intense peaks at 2922 and $2852 \mathrm{~cm}^{-1}$ are from the asymmetric and symmetric stretching vibrations of $-\mathrm{CH}_{2}-$ groups; finally, the peak at $3006 \mathrm{~cm}^{-1}$ is from a characteristic stretching vibration of the $\mathrm{C}-\mathrm{H}$ bond, next to the $\mathrm{C}=\mathrm{C}$ double bond. FTIR spectra evidence that signals corresponding to the $\mathrm{C}-\mathrm{H}$ bond stretching nearly disappear after ligand exchange (PbS$\mathrm{MAPbI}_{3}$ ). The residual intensity could originate from the $\mathrm{CH}_{3}$ - group of methylammonium cations or from solvents residues. Notably, the signal from the $\mathrm{C}-\mathrm{H}$ stretching next to the double $\mathrm{C}=\mathrm{C}$ bond at $3006 \mathrm{~cm}^{-1}$ is not present in the FTIR spectrum of the dried residue of the nonpolar phase (long-chain organic ligands). Similarly, the signal from hydrogens next to the double bond at $5.3 \mathrm{ppm}$ is also absent in the ${ }^{1} \mathrm{H}$ NMR spectrum of the dried nonpolar phase (Figure S1, Supporting Information). This absence may indicate that oleate does not migrate into the hexane phase during the washing steps but stays as a salt (methyl ammonium oleate or lead oleate) in a polar NMF phase and separated by a second stage of purification by precipitation of the exchanged QDs.

The broadband signature at around $3450 \mathrm{~cm}^{-1}$ usually comes from hydrogen-bonded $\mathrm{OH}-$ groups, so it can be present in the spectra because of $\mathrm{H}_{2} \mathrm{O}$ absorbed from air into the $\mathrm{KBr}$ pellet or from the surface $\mathrm{Pb}-\mathrm{OH}$ species. ${ }^{49,50}$ The stretching vibration modes from $\mathrm{N}-\mathrm{H}$ bonds of methylammonium cations are also in this region, making the assignment of the different signals present in $\mathrm{PbS}$ QDs after ligand exchange difficult.

Free oleic acid has an intense characteristic signal at 1712 $\mathrm{cm}^{-1}$ coming from the stretching of the $\mathrm{C}=\mathrm{O}$ double bond. This signal is naturally absent in the FTIR spectrum of PbS QDs covered with oleic acid, but instead, two signals at 1534 and $1402 \mathrm{~cm}^{-1}$ coming from asymmetric and symmetric stretches of $\mathrm{COO}^{-}$, respectively, are present. The wavenumber difference between the two peaks of $\mathrm{COO}^{-}$group (at 1534 and $1402 \mathrm{~cm}^{-1}$ ) is $132 \mathrm{~cm}^{-1}$, indicating different coordination modes of $\mathrm{OA}$ to $\mathrm{PbS} \mathrm{QDs}$ surface while the bridging coordination is the major coordinating mode. ${ }^{51}$ The peaks corresponding to the $\mathrm{COO}^{-}$group are absent in the FTIR spectrum of $\mathrm{PbS}$ after ligand exchange. Also, the $\mathrm{C}=\mathrm{O}$ signal is absent in the FTIR spectrum of $\mathrm{PbS} \mathrm{QDs}$ after ligand exchange, so it could be stated that, in our sample, there is no (below detection limit) unwashed free oleic acid between QDs after ligand exchange. However, the signal from $\mathrm{C}=\mathrm{O}$ is also absent in the organic residue obtained from the dried hexane phase, so it could mean that the ligands desorb from the QDs surface not in the form of acid. In agreement with this observation the triplet signal from the protons next to the carboxylic group at $2.35 \mathrm{ppm}$ characteristic for the oleic acid is absent in the ${ }^{1} \mathrm{H}$ NMR spectrum of the dried hexane phase (Figure S1). More details of the FTIR signals assignments can be found in Table S1. 


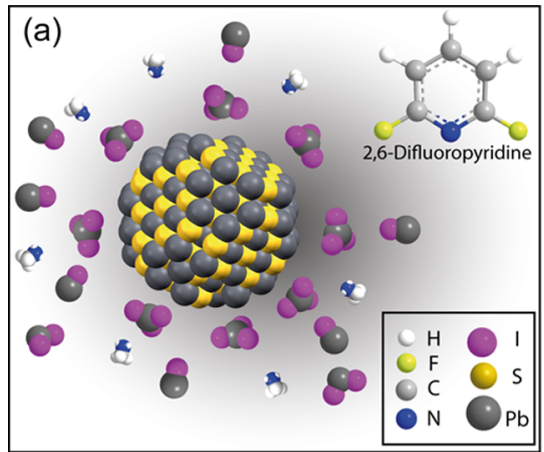

(c)
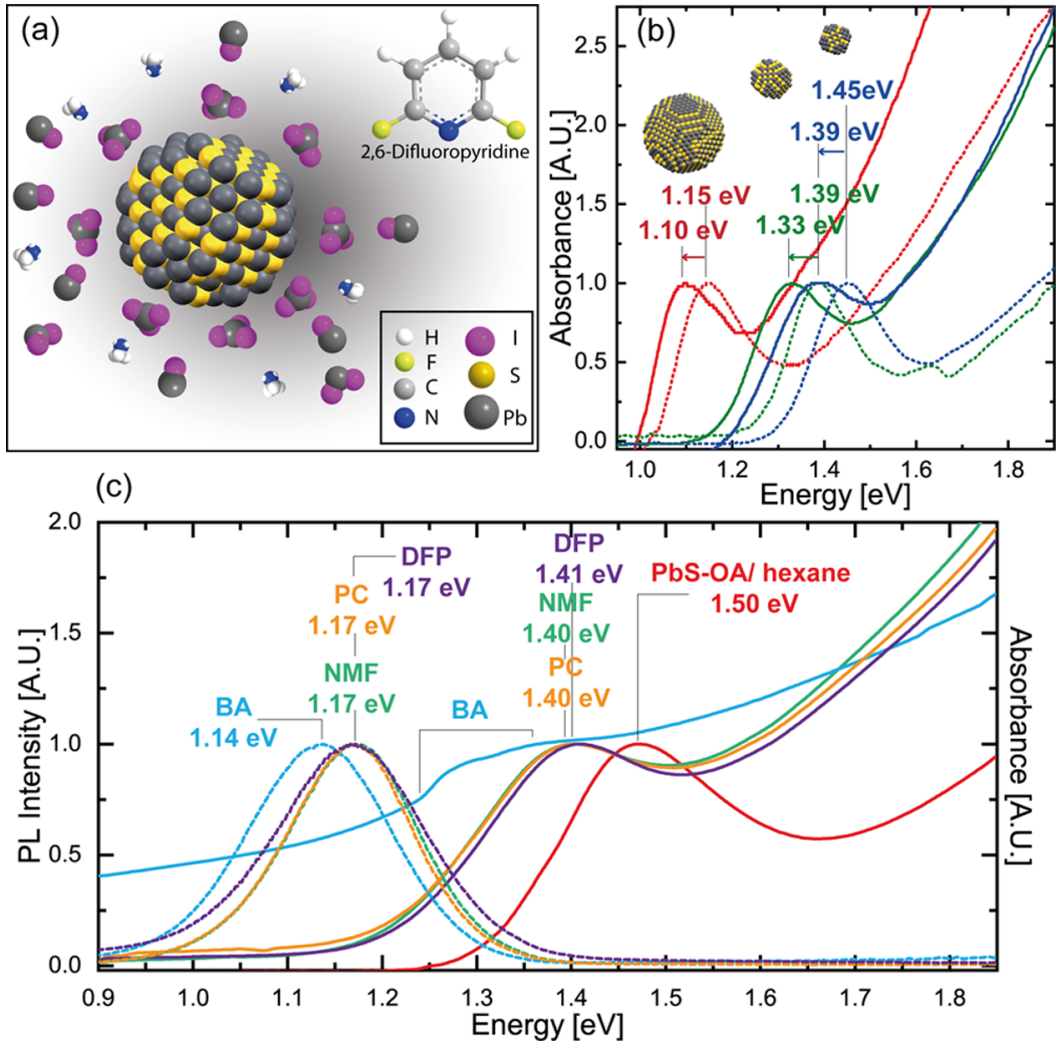

Figure 2. (a) Schematic representation of the stabilization of the $\mathrm{PbS}-\mathrm{MAPbI}_{3}$ quantum dot inks in 2,6-difluoropyridine. (b) Absorption spectra of the various sizes of $\mathrm{PbS}$ quantum dots in hexane before the ligand exchange (dashed lines) and inks in DFP (solid lines). (c) Absorption (solid lines) and PL spectra (dashed lines) of the PbS quantum dots in various solvents.

Colloidal stabilization after the ligand exchange relies on the electrostatic interaction between the charged surface of the nanocrystal and ions in its surroundings (Figure 2a). The solvent should be polar enough (to have a high static dielectric constant) to support the ligand system in the ionized state. The ligand precursor dissociation, anion adsorption onto the $\mathrm{PbS}$ QD surface, the solvation of cations, and the formation of the electrostatic double layer around the QDs by counterions from the solution in highly polar solvents lead to colloidal electrostatic stabilization. In our system, the surface of $\mathrm{PbS}$ QDs becomes negative due to binding with $\mathrm{PbI}_{3}{ }^{-}$and (or) $\mathrm{PbI}_{4}{ }^{2-}$ anions, while the diffuse layer of counterions is most likely formed by the $\mathrm{CH}_{3} \mathrm{NH}_{3}{ }^{+}$and $\mathrm{PbI}^{+}$cations. The solvent Lewis acidity and donor number also play a significant role. ${ }^{36}$ The acidity of the solvent correlates with the efficiency of anion solvation. Thus, if the solvent is a strong Lewis acid, it will have a stronger interaction with the anions, making the bonding of anions to the QD surface more difficult (decreasing the colloidal stability). On the other hand, the solvent's donor number or Lewis basicity is associated with the ability of the solvent to solvate cations. If the cations are effectively solvated, anions will be not desorbed from the QD surface.

In our study, for the implementation of $\mathrm{PbS} \mathrm{QD}$ inks in solar cells, we have used nanocrystals with the first excitonic peak at $1.47 \mathrm{eV}(844 \mathrm{~nm})$, which corresponds to particles with a diameter of about $2.7 \mathrm{~nm}$ (Figure $2 \mathrm{c}$ and Table 1). After ligand exchange and transfer of the $\mathrm{PbS} \mathrm{QDs}$ to $\mathrm{NMF}$, the first excitonic peak in the absorption spectrum shifted to $1.40 \mathrm{eV}$ $(885 \mathrm{~nm})$, with an increased FWHM. The redshift can be explained either by an increase in the effective size of nanocrystals due to the inorganic ligand shell formed on the
Table 1. Absorption and Emission Peak Positions and Stokes Shift for the PbS QDs in the Different Solvents

\begin{tabular}{|c|c|c|c|c|c|c|}
\hline \multirow[b]{2}{*}{ solvent } & \multicolumn{2}{|c|}{ absorption } & \multicolumn{2}{|c|}{ emission } & \multicolumn{2}{|c|}{ Stokes shift } \\
\hline & $\mathrm{eV}$ & $\mathrm{nm}$ & $\mathrm{eV}$ & $\mathrm{nm}$ & $\mathrm{meV}$ & $\mathrm{nm}$ \\
\hline hexane (original $\mathrm{PbS}-\mathrm{OA}$ ) & 1.47 & 844 & & & & \\
\hline $\begin{array}{l}\text { NMF (the polar phase } \\
\text { after LE) }\end{array}$ & 1.40 & 885 & 1.17 & 1060 & 230 & 175 \\
\hline$n$-butylamine (BA) & & & 1.14 & 1088 & & \\
\hline propylene carbonate (PC) & 1.40 & 885 & 1.17 & 1060 & 230 & 175 \\
\hline $\begin{array}{l}\text { 2,6-difluoropyridine } \\
\text { (DFP) }\end{array}$ & 1.41 & 880 & 1.17 & 1060 & 230 & 180 \\
\hline
\end{tabular}

surface, or by the change in the dielectric permittivity of the solvent, or by the aggregation of the QDs in solution, which does not compromise the colloidal stability. ${ }^{47}$

$\mathrm{NMF}$ is one of the best choices for the ligand exchange with $\mathrm{MAPbI}_{3}$ because it has a very high dielectric constant (182.4); thus, QD dispersions do not lose their colloidal stability. NMF is also a good Lewis acid, so it can efficiently solvate the anions. For this reason, it is not suitable for the preparation of very diluted $\mathrm{PbS}-\mathrm{MAPbI}_{3}$ dispersions because it will start to desorb $\mathrm{PbI}_{3}{ }^{-}$anions from the QD surface. ${ }^{36}$ On the other hand, NMF has a high boiling point of $182.5^{\circ} \mathrm{C}$, which makes it non-ideal for the deposition of films with the thickness and quality required for photovoltaic devices. After the ligand exchange, the pellet of $\mathrm{PbS}$ quantum dots can be re-dissolved in a solvent acceptable for ink deposition and storage. Some of the common polar solvents can be potentially considered for this purpose. Table S2 reports some important parameters, which should be considered for PbS QD inks. DMSO and DMF (often used for ligand exchange) are both much less polar than 
NMF ( $\varepsilon=46.7$ and 37.1 , respectively) but still relatively polar. DMSO has an even higher boiling point than NMF (189.0 ${ }^{\circ} \mathrm{C}$ ), while DMF has a slightly lower boiling point $\left(153.0^{\circ} \mathrm{C}\right)$. It is, however, not possible to re-dissolve the $\mathrm{PbS} \mathrm{QD}$ pellets in both solvents after ligand exchange and centrifugation.

In a previous study, we have used propylene carbonate (PC) for the formation of inks. ${ }^{48}$ From the absorption spectrum of the solution, it is clear that the first excitonic peak does not shift after the substitution of the washed NMF phase (with an excess of inorganic ligands used for the ligand exchange) with PC. PC is also rather polar $(\varepsilon=62.9)$, and it is also a weaker Lewis acid than NMF, which ensures the long-term stability of the inks (also at very low concentrations), as reported in a recent publication from our group. ${ }^{47}$ However, it has an even higher boiling point than NMF, $242{ }^{\circ} \mathrm{C}$.

In the literature the most common solvent for $\mathrm{PbS}$ QD inks deposition is $n$-butylamine (BA). BA exchanges protons $\mathrm{H}^{+}$ with $\mathrm{MA}^{+}$and ionically binds to the anionic surface. Colloidal stabilization is steric in this case, but BA is short and therefore cannot provide good steric repulsion and colloidal stability. The main advantage of BA is the low boiling point $\left(\sim 78{ }^{\circ} \mathrm{C}\right)$; thus, it can be easily used for inks deposition by spin coating. On the other hand, it has a very low dielectric constant $(\varepsilon=$ 4.9) and, therefore, $\mathrm{PbS}-\mathrm{MAPbI}_{3}$ QDs are not colloidally stable in BA. Moreover, it is known, that BA tends to etch $\mathrm{PbS}$ nanocrystal's surface causing $\mathrm{QD}$ aggregation and precipitation. ${ }^{52}$ As mentioned above, when using PbS QD inks for the deposition of solar cell active layers, it is important to find a proper compromise between a high dielectric constant for ink stability and low boiling temperature for easier deposition. 2,6Difluoropyridine (DFP) was selected as the solvent in this work. It is characterized by a high dielectric constant $(\varepsilon=$ 107.8) due to the electronegative fluorine atoms in the structure, while the boiling point is relatively low when compared to other high dielectric constant solvents (124.5 $\left.{ }^{\circ} \mathrm{C}\right)$. QDs in this solvent show that the signal from the first excitonic peak is slightly shifted with respect to the first excitonic peak in NMF (1.41 eV or $880 \mathrm{~nm})$. This can be explained by the slightly different dielectric environment. For all the used solvents, namely, NMF, PC, and DFP, the emission peak in the steady-state PL spectra (Figure 2c) is at $1.17 \mathrm{eV}(1060 \mathrm{~nm})$. The PL peak from the DFP inks is slightly broader than in NMF and PC, which may be due to a different degree of clustering of the QDs in solution. The PL signal from the inks in $\mathrm{BA}$ is redshifted to $1.14 \mathrm{eV}$, which supports the point that QDs rapidly aggregate in this solvent.

As mentioned before, a serious concern in the literature is the stability of $\mathrm{PbS}$ QD inks made with larger ${ }^{41}$ particle sizes, which are interesting for application such as IR detection and IR absorption layers in tandem solar cells. ${ }^{53}$ It is interesting to note that, in our case, the inks prepared from different particle sizes are all stable in DFP. This is best seen in Figure $2 b$, which shows the absorption spectra of PbS QDs of different sizes before and after ligand exchange in DFP (the absorption peak positions for the original colloidal solutions of oleic acid capped $\mathrm{PbS}$ and the inks after ligand exchange with $\mathrm{MAPbI}_{3}$ are shown in Table 2). The first excitonic peak is redshifted and slightly broadened after ligand exchange for all three particle sizes. Additionally, the PbS QDs inks are stable in DFP in a wide range of concentrations from 0.5 to $\sim 300 \mathrm{mg} \mathrm{mL}^{-1}$. Compare to, for example, DMF or BA where particles precipitate within minutes at low concentrations (below 10 $\mathrm{mg} \mathrm{mL}{ }^{-1}$ ).
Table 2. Absorption Peak Positions for the Original Colloidal Solutions of PbS QDs with Oleic Acid and the Inks after Ligand Exchange with $\mathrm{MAPbI}_{3}$ and the Shift of the Absorption Peak after LE

\begin{tabular}{|c|c|c|c|c|c|c|}
\hline \multirow{2}{*}{$\begin{array}{l}\text { QD diameter before LE, } \\
\mathrm{nm}\end{array}$} & \multicolumn{2}{|c|}{$\begin{array}{l}\text { absorption } \\
\text { before LE }\end{array}$} & \multicolumn{2}{|c|}{$\begin{array}{l}\text { absorption } \\
\text { after LE }\end{array}$} & \multicolumn{2}{|c|}{ shift } \\
\hline & $\mathrm{eV}$ & $\mathrm{nm}$ & $\mathrm{eV}$ & $\mathrm{nm}$ & $\mathrm{meV}$ & $\mathrm{nm}$ \\
\hline 3.6 & 1.15 & 1078 & 1.10 & 1129 & 50 & 51 \\
\hline 2.9 & 1.39 & 893 & 1.33 & 932 & 60 & 39 \\
\hline 2.7 & 1.45 & 855 & 1.39 & 892 & 60 & 37 \\
\hline
\end{tabular}

The most used technique nowadays to deposit relatively thick (order of hundreds of nanometers) and homogeneous layers of $\mathrm{PbS} \mathrm{QDs}$ is spin coating. However, for spin coating, a low boiling point solvent is preferable, and out of all the solvents taken into consideration in this work, only BA is appropriate for this purpose. However, spin coating is not an industrially friendly technique for solar cell fabrication and it is very wasteful. At the opposite, blade coating (Figure 3a) is a scalable laboratory technique, which is closely related to industrial-level techniques such as roll-to-roll printing. Blade coating entails the spreading of the solution over the substrate by a blade. The thickness and morphology of the film can be controlled by the speed of the blade, the distance between the blade and substrate, the deposition temperature (controlled by the plate temperature), and the solution concentration. By optimizing the blade-coating parameters of DFP-based inks, we were able to achieve good film quality (Figure $3 \mathrm{~b}$ ) at relatively low processing temperatures $\left(70-100{ }^{\circ} \mathrm{C}\right)$. Table S5 and its description compare the inks consumptions required for film fabrication by the blade coating and spin coating. It also summarizes the prices of the solvents used for the ink production. DFP is relatively expensive, and we believe the reason for this is that this molecule is generally not considered as a solvent. Thus, it is produced on a very low scale. Therefore, the price cannot be compared with one of the solvents produced in bulk quantities. We suspect that using a relatively small amount of DFP justifies the investment of huge volumes of anhydrous solvents, CQDs, and chemicals for the ligands if the ink can be stored for a prolonged period of time.

In our previous report, ${ }^{48}$ the single-step fabrication of field effect transistors from PC-based $\mathrm{PbS} \mathrm{QD}$ inks has been shown. For these devices, a deposition temperature of $100{ }^{\circ} \mathrm{C}$ has been used, and the obtained film thicknesses were in the range of 20-40 nm. However, for solar cells, much thicker films are required. DFP-based inks allowed us to obtain films of 100$300 \mathrm{~nm}$ already at $70{ }^{\circ} \mathrm{C}$ by a single blade-coating step.

Figure $3 \mathrm{c}$ shows the PL and absorption spectra of the PbS QD film blade-coated on glass from DFP inks. The absorption spectrum shows a peak at $1.36 \mathrm{eV}$, which is due to the first excitonic peak of the QDs, slightly shifted from the position measured in DFP solution $(1.41 \mathrm{eV})$, and a second peak is visible at $0.8 \mathrm{eV}$. This second peak is within the material bandgap, so it can be explained by different mechanisms. The first and most plausible one is the epitaxial merging of several QDs that give rise to domains of narrower band-gap material within the film. The second less plausible one originates from trap states. ${ }^{8}$ Trap states generally have a very small cross section for absorption, and they are therefore evidenced generally only by PL spectroscopy. Interestingly, the PL spectrum also displays two features at 0.8 and $1.1 \mathrm{eV}$. While 


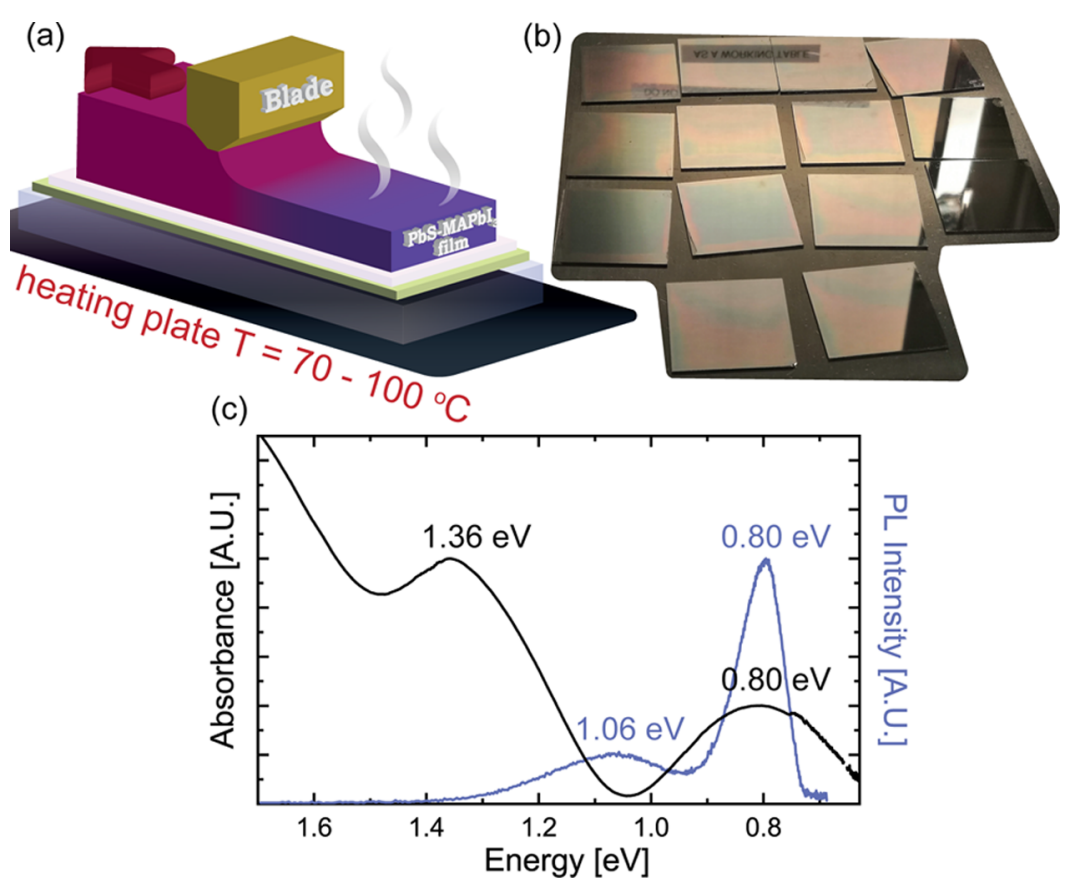

Figure 3. Blade-coated films of PbS-MAPbI ${ }_{3}$ inks from DFP. (a) Scheme of the blade-coating process. (b) Photograph of the blade-coated films

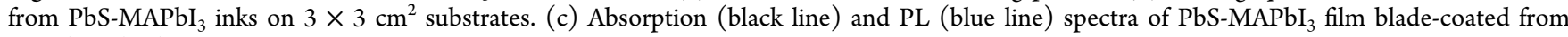
DFP-based inks.

the peak at $1.1 \mathrm{eV}$ is related to the excitonic peak, that in solution has an energy of $1.17 \mathrm{eV}$, and the second peak corresponds to the low energy peak of the absorption spectrum. Again, the most plausible origin of the low energy peak is the epitaxial merging of several QDs, which is favored by the elevated temperature of the deposition process.

To evaluate the film morphology at the nanoscale, we performed AFM measurements. The quality of the $\mathrm{PbS} \mathrm{QD}$ blade-coated films is compared with that of the $\mathrm{PbS}$ films used as the hole transporting layer (HTL) in the same device structure but deposited by LbL spin coating. Figure 4a shows the morphology of the PbS-MAPbI ${ }_{3} \mathrm{QD}$ film blade-coated from DFP, Figure $4 \mathrm{~b}$ shows the micrograph of the $\mathrm{PbS}$ QDs treated with 1,2-ethanedithiol (EDT) ligands and deposited using the LbL spin-coating method on top of the blade-coated $\mathrm{PbS}-\mathrm{MAPbI}_{3}$ layer (as in the real device), and Figure 4c shows the morphology of the PbS-EDT layer deposited on ITO by the LbL spin-coating method. An RMS value of $1.5 \mathrm{~nm}$ was derived from the AFM micrograph (of $1 \mu \mathrm{m}^{2}$ area) of the blade-coated film from $\mathrm{PbS}-\mathrm{MAPbI}_{3}$ DFP-based inks, showing the excellent quality of the film especially taking into account the thickness of the average PbS QD solar cell $(100-300 \mathrm{~nm})$. The RMS of the PbS-EDT film on top of the blade-coated $\mathrm{PbS}-\mathrm{MAPbI}_{3}$ layer is slightly higher $(2.7 \mathrm{~nm})$, while the roughness of the PbS-EDT film spin-coated directly on ITO is $1.8 \mathrm{~nm}$.

Interestingly, in all of the AFM micrographs, we can see features of $15-35 \mathrm{~nm}$ in size, which are probably domains caused by quantum dot aggregation. These features are also clearly visible on the AFM images of PbS QD films deposited by various methods reported by various authors, for example, on films deposited by the layer-by-layer spin coating with TBAI. $^{54}$ The formation of these aggregates can support the appearance of the peak at $0.8 \mathrm{eV}$ in the absorption and $\mathrm{PL}$ spectra of the films in Figure 3.
The interest in the development of colloidally stable $\mathrm{PbS}$ inks, which can be deposited at low temperatures, is pushed by the aim of fabricating solar cells by R2R or similar large-scale facilities without losing the quality of the film during the ink deposition process. After careful stability study and deposition optimization, we tested our DFP-based inks in solar cells. The device structure used for this study is shown in Figure 5a. It includes a glass substrate with ITO transparent contacts, a layer of $\mathrm{ZnO}$ nanocrystals, serving as an electron transport layer (ETL), the blade-coated n-type PbS-MAPbI ${ }_{3}$ DFP-based QD ink, a layer of PbS QDs with EDT ligands as the p-type layer, and an Au electrode as back contact. The PbS-EDT layer is deposited by the not-scalable LbL, but it can potentially be replaced in the future by other solution-processable inks, which can be cast in one step. ${ }^{45}$

Figure $5 b$ shows the cross-sectional image of our most efficient solar cell with the n-type layer blade-coated from DFP-based PbS QD inks. For the cross-sectional image of the device, we have prepared a focused ion beam (FIB) lamella and investigated it using high-angle annular dark field (HAADF) scanning transmission electron microscopy (STEM) mode (the Experimental Section contains more details about lamella preparation and STEM measurements). From the cross-sectional view, we deduce the thicknesses of each layer. Thus, the thickness of the ITO layer is $115 \mathrm{~nm}$, the $\mathrm{ZnO}$ layer is $60 \mathrm{~nm}$, the $\mathrm{PbS}-\mathrm{MAPbI}_{3}$ active layer is $120 \mathrm{~nm}$, the PbS-EDT layer is $60 \mathrm{~nm}$, and $\mathrm{Au}$ is $80 \mathrm{~nm}$. A wider view of the cross section of the solar cell is shown in Figure S4, which confirms the homogeneity of the layers on a larger scale. It is interesting to notice the darker color of the PbS-EDT layer in the STEM images with respect to the $\mathrm{PbS}-\mathrm{MAPbI}_{3}$. This can be explained by the different content of elements with high atomic numbers. Since, in STEM, electrons scatter onto the HAADF detector with an intensity proportional to $\mathrm{Z}^{2}$ or density $^{2}$, the PbS-EDT layer is probably less dense. The energy-dispersive X-ray spectroscopy (EDS) elemental analysis 

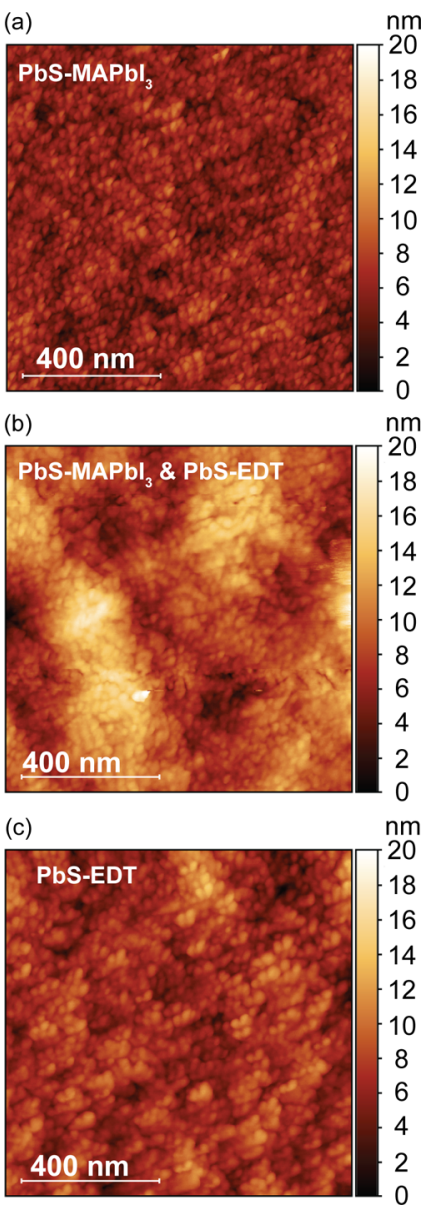

Figure 4. AFM images of (a) $\mathrm{PbS}-\mathrm{MAPbI}_{3}$ inks blade-coated from DFP, (b) morphology of the complete device $\mathrm{PbS}-\mathrm{MAPbI}_{3}$ active layer with the PbS-EDT film on top, and (c) the PbS-EDT film made by the LbL approach using the spin-coating technique.

mapping of the lamella can be found in Figure S5. The EDS spectra of each layer are shown in Figure S6. The mapping shows a larger fraction of $\mathrm{Pb}$ atoms for the $\mathrm{PbS}$-EDT layer than in the $\mathrm{PbS}-\mathrm{MAPbI}_{3}$. The slightly lower fraction of lead, together with a larger content of carbon in the PbS-MAPbI layer, can be explained by the decoration of the $\mathrm{PbS}$ QDs with the methylammonium. Although the iodide atomic fraction is clearly bigger in the $\mathrm{PbS}-\mathrm{MAPbI}_{3}$ layer, the iodide signal in the $\mathrm{PbS}$-EDT layer is somehow surprising and may be explained by diffusion from the layer underneath. It is also interesting to note that each sublayer of about $20 \mathrm{~nm}$ of the PbS-EDT, deposited using the layer-by-layer technique, can be resolved. These extra "interfaces" can be a source of defects and act as recombination centers in the full device.

Figure $5 \mathrm{c}$ and Figure $5 \mathrm{~d}$ show magnified views of the cross section of $\mathrm{PbS}-\mathrm{EDT}$ and $\mathrm{PbS}-\mathrm{MAPbI}_{3}$ layers, respectively, where atomic resolution can be appreciated when zooming in. The size of the PbS-EDT nanocrystals is roughly unchanged after deposition $(\sim 3 \mathrm{~nm})$, and a closer look at Figure $5 \mathrm{~b}$ shows the orientation of the $\mathrm{PbS}$ QDs. In the $\mathrm{PbS}-\mathrm{MAPbI}_{3}$ films, there is no evidence of long-range ordering, but especially in Figure 5d, the crystals look clustered, with cluster sizes around 8-10 nm. Although careful sequential analyses during FIB sample preparation (with a final low energy milling of $2 \mathrm{kV}$ ), TEM imaging (with a lower dose), STEM imaging (with a higher dose), and STEM-EDS mapping (with the highest dose) did not show signs of sample degradation, it cannot be fully ruled out that FIB sample preparation and/or the high energy electrons $(300 \mathrm{kV})$ used for the STEM imaging influenced the clustering and atomic structure details observable in Figure 5c,d.

There are several studies in the literature, where similar combinations of ligands were used (stoichiometric MAI and $\mathrm{PbI}_{2}$ or CsI and $\mathrm{PbI}_{2}$ ), which can give perovskites as a product. Several authors reported that the perovskite crystal lattice is formed on top of the PbS nanocrystals due to the very close match of the lattice parameters between $\mathrm{PbS}$ and metal halide perovskites $\left(\mathrm{MAPbI}_{3}\right.$ or $\left.\mathrm{CsPb}_{3}\right)$. However, from our HAADFSTEM cross-sectional image, it is difficult to say anything about the presence of a perovskite matrix formation between the $\mathrm{PbS}$ nanocrystals. Figure $\mathrm{S} 3$ shows the XRD powder diffraction measurement of $\mathrm{PbS}-\mathrm{OA}$ and $\mathrm{PbS}-\mathrm{MAPbI}_{3}$ thin films. In these measurements, only the $\mathrm{PbS}$ crystal phase is resolved; after ligand exchange, the XRD signals from crystal planes such as (002), (004), and (024) become more prominent, which is an indication of crystal alignment in the clustering after ligand treatment, as has been reported earlier. ${ }^{4}$ Here, it is important to note that, if only a monolayer of perovskite is forming on top of the $\mathrm{PbS}$ nanocrystals, it would not be possible to detect it both with HRTEM and XRD.

Figure 6 summarizes the behavior of our best solar cell blade-coated from DFP inks. In Figure 6a, the $J V$ measurement under solar-simulated AM1.5G illumination at the intensity of $1000 \mathrm{Wm}^{-2}$ in forward and reverse directions are shown. The hysteresis in the $J V$ measurements is quite low if we compare it with the $J V$ measurements of devices with similar ligands spincoated from BA. ${ }^{16}$ The inset in Figure 6a shows the $J V$ measurement of the same device in the dark showing a very high diode quality, with a rectification ratio $\left(J_{V=1} / J_{V=-1}\right)$ of 6.8 $\times 10^{5}$. The device parameters in the forward and reverse sweeps are listed in Table 3. The $J_{\mathrm{SC}}$ of our best device is higher than in devices with the same ligands made by spin coating from BA, ${ }^{16} 25.1 \mathrm{~mA} \mathrm{~cm}{ }^{-2}$ vs $21.9 \mathrm{~mA} \mathrm{~cm}^{-2}$, while our device is slightly thinner. At the same time, our device bladecoated from DFP shows a slightly lower $V_{\mathrm{OC}}(0.57 \mathrm{~V})$ than spin-coated devices from BA $(0.61 \mathrm{~V})$, which may be due to QD aggregation during the deposition procedure from DFP. Our best device has an FF of 0.61 and a similar power conversion efficiency of champion devices made with QDs of the same size, with the same ligands by spin coating from BA inks $(8.7 \%$ vs $8.5 \%) .^{16}$

We should also note the good device stability under illumination of solar cells made from DFP-based PbS QD inks as well as remarkable air stability. In Figure S8a, we demonstrate that the device parameters did not change after keeping the devices under light soaking for more than $1 \mathrm{~h}$. The experiment was performed after this device was already aged in air for 97 days. Figure S8b shows the behavior of the same device after 100 days under ambient conditions.

Figure $6 \mathrm{~b}$ shows the EQE spectrum of the same device as in Figure $6 \mathrm{a}$, together with the integrated short-circuit current density of $22 \mathrm{~mA} \mathrm{~cm}^{-2}$. Light intensity dependences of the $J_{\mathrm{SC}}$ and $V_{\mathrm{OC}}$ are reported in Figure $6 \mathrm{c}$ and show that the linearity of the photocurrent with the light intensity $J_{\mathrm{PH}} \approx I^{\alpha}$ is close to 1 , the ideal situation. The diode ideality factor $n$ can be extracted from the light intensity dependence of $V_{\mathrm{OC}}$. In our best device, it is 1.47, indicating that both bimolecular recombination and trap-assisted recombination take place in this solar cell. Figure $6 \mathrm{~d}$ presents the $J V$ measurements of the 

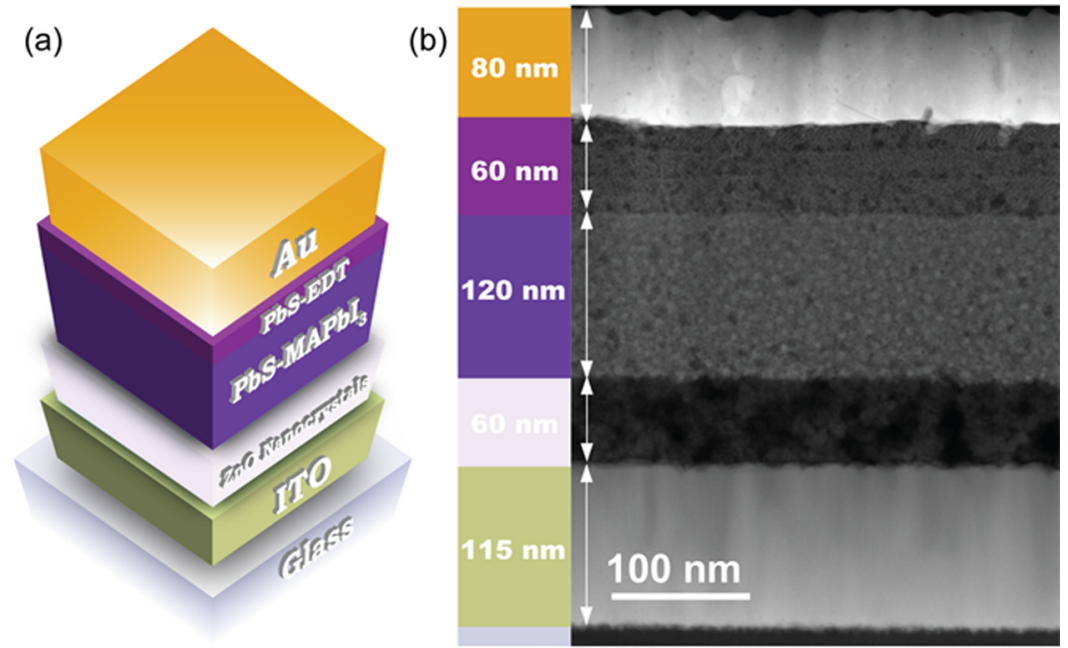

(c)

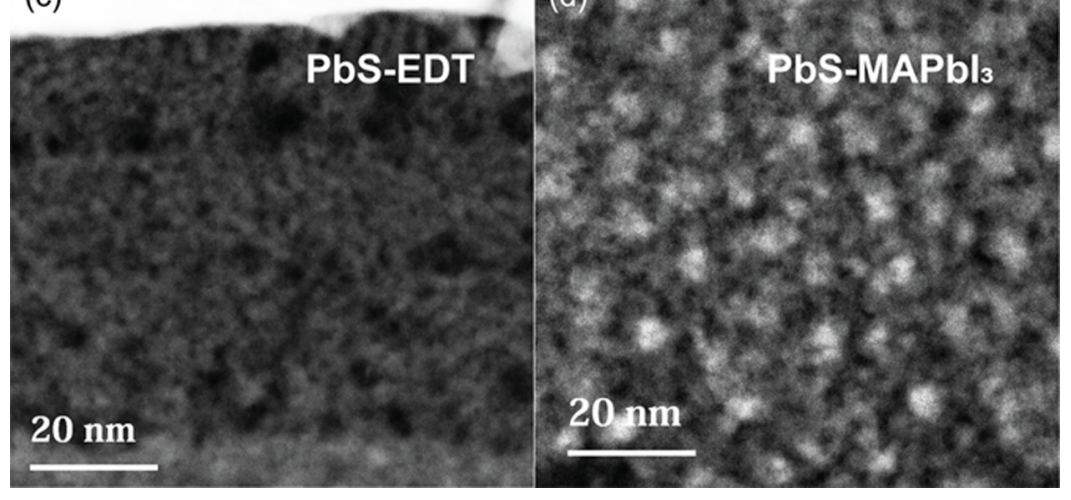

Figure 5. (a) Structure of the solar cell. (b) Cross-sectional HAADF-STEM micrograph of a complete device. Magnified view of the layers of the cross section: (c) PbS-EDT and (d) PbS-MAPbI ${ }_{3}$.

device made from fresh ink, the same device after storage in air (which show improved performances due to the increase in $V_{\mathrm{OC}}$ and FF), and a similar device, made from the same DFPbased ink aged for 125 days (without storing the device in air). We can conclude that even after 4 months of ink storage, we can make devices of good quality ( $5.8 \%$ efficiency) while BAbased inks cannot be stored even for a few hours.

Figure 7 shows the histograms of the figures of merits for a large number of solar cells. Devices with a power conversion efficiency from $4.5 \%$ to $\sim 9 \%$ can be fabricated. This large spread in efficiency is mostly due to the spread in the $J_{\mathrm{SC}}$, most probably due to the thickness variation. This is consistent with Figure $3 \mathrm{~b}$, where some differences of the blade-coated film color can be observed due to thickness inhomogeneity. Some rearrangement (wrinkling or shrinking in the very extreme cases) in the film's morphology is happening after the blade has passed over the substrate. These effects can be explained by the surface energy of the substrate material on which the inks are deposited and the ability of the inks to wet the surface. If the wetting is not very good and the deposition temperature is not high enough, the ink can shrink into a liquid droplet before it dries in the "film state". For the DFP-based inks deposited on $\mathrm{ZnO}$, a plate temperature between 70 and $100{ }^{\circ} \mathrm{C}$ gives the most reliable results. Further increasing the deposition temperature makes the evaporation of the solvent too fast and damages the morphology of the film. Despite some thickness inhomogeneity, we can still praise the strategy for the scalable fabrication of $\mathrm{PbS} \mathrm{QD}$ solar cells. In Figure S9, we show the $J V$ measurements of the devices with larger areas $\left(0.25 \mathrm{~cm}^{2}\right.$ in Figure S9a and $0.8 \mathrm{~cm}^{2}$ in Figure S9b), and Table S3 summarizes the average solar cell's parameters over seven devices of area $=0.25 \mathrm{~cm}^{2}$ made on different substrates. All the results show that, by blade-coating deposition, we can reproducibly fabricate solar cells with areas approaching 1 $\mathrm{cm}^{2}$ with reasonable (4.3\%) performances. Figure S10a demonstrates the device performance of 4 pixels of $0.1 \mathrm{~cm}^{2}$ active area deposited on the ITO substrate with a geometry as in Figure S10b. Thus, we can conclude that, on a scale of $1.5 \times$ $1.5 \mathrm{~cm}^{2}$, film thickness inhomogeneity can be ignored, while on the bigger scales, it can probably average over the whole surface area and do not play anyhow a significant role. Table $\mathrm{S} 4$ reports the device parameters extracted from $J V$ measurements, shown in Figure S10a. Furthermore, the problem of inhomogeneous morphology could be solved by changing the wettability of the substrate (modifying the $\mathrm{ZnO}$ surface or replacement of $\mathrm{ZnO}$ with another ETL) and by changing the quality of the inks by adding surfactants.

\section{CONCLUSIONS}

In conclusion, we propose a strategy of scalable fabrication of $\mathrm{PbS} \mathrm{QD}$ solar cells from colloidally stable $\mathrm{PbS}$ QD inks at relatively low temperatures $\left(70{ }^{\circ} \mathrm{C}\right)$, which became possible after careful selection of the solvent for the $\mathrm{PbS} \mathrm{QD}$ ink dispersions. DFP is an exceptional and rare solvent, thanks to two electronegative fluorine atoms in the 2 and 6 positions, and combines both a high dielectric constant and a relatively 

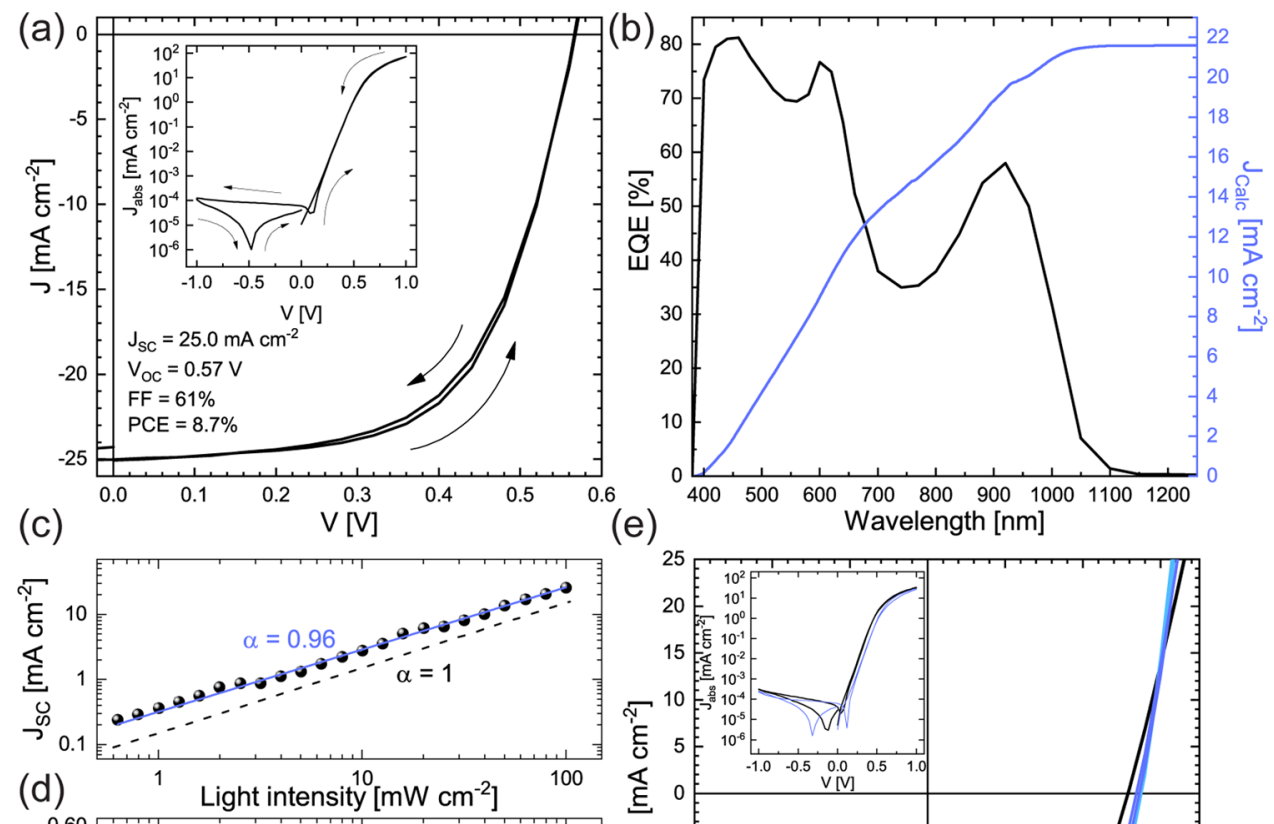

(e)

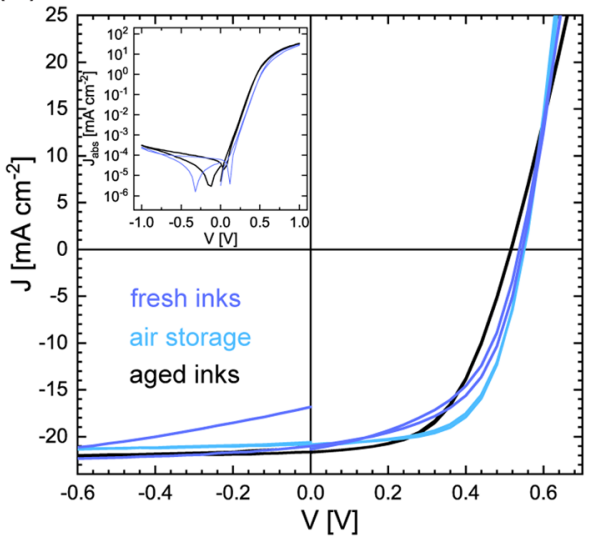

Figure 6. Device characterization: (a) $J V$ measurements of the record $\mathrm{PbS}$ QD solar cell blade-coated from the $\mathrm{PbS}-\mathrm{MAPbI}_{3} / \mathrm{DFP}$ inks; the inset shows $J V$ measurements of the same devices in the dark. (b) EQE spectrum of the same devices as in (a). Illumination intensity dependence characteristics of solar cells: (c) of the short circuit current density and (d) of the open-circuit voltage. (e) $J V$ characteristics or the devices made from fresh inks (violet curve) and the inks stored for 124 days (black curve). The blue curve indicates the same device as on bright violet but stored in air for 97 days.

Table 3. Figures of Merit in Forward and Reverse Sweeps of the Best PbS-MAPbI ${ }_{3}$ QD Solar Cell Blade-Coated from DFP Inks

\begin{tabular}{lcccc} 
& $J_{\mathrm{SC}}\left[\mathrm{mA} \mathrm{cm}^{-2}\right]$ & $V_{\mathrm{OC}}[\mathrm{V}]$ & $\mathrm{FF}$ & $\mathrm{PCE}[\%]$ \\
forward & 25.1 & 0.57 & 0.60 & 8.5 \\
reverse & 25.0 & 0.57 & 0.61 & 8.7 \\
\hline
\end{tabular}

low boiling point. We showed that blade coating, which is much more appropriate for the casting of large areas than spin coating, can be used for the active layer deposition without any loss of efficiency. In addition, the ink's high colloidal stability enables continuous production of solar cells without any largescale inhomogeneity in the active layer quality throughout the area of the device. By adjusting the blade-coating parameters, we optimized the deposition process and confirmed by STEM and AFM that the active layer quality and morphology are similar to that of the spin-coated devices. We showed that it is possible to produce large-area, smooth, mirror-like $\mathrm{PbS} \mathrm{QD}$ films by blade coating. Our PbS QD solar cells are comparable in performance (PCE of $8.7 \%$ ) to the devices made by spin coating from the $\mathrm{PbS} \mathrm{QD}$ inks with the same ligands $(8.5 \%)$.

Notably, the DFP solvent can stabilize PbS QD dispersions with different $\mathrm{QD}$ sizes. Large $\mathrm{PbS} \mathrm{QDs}$, interesting for IR absorption applications, have different surface chemistry and are usually more prone to aggregation after ligand exchange. DFP efficiently stabilizes $\mathrm{PbS}-\mathrm{MAPbI}_{3}$ inks with QDs ranging from 2.7 to $3.7 \mathrm{~nm}$, corresponding to excitonic absorption peaks from 840 to $1100 \mathrm{~nm}$.
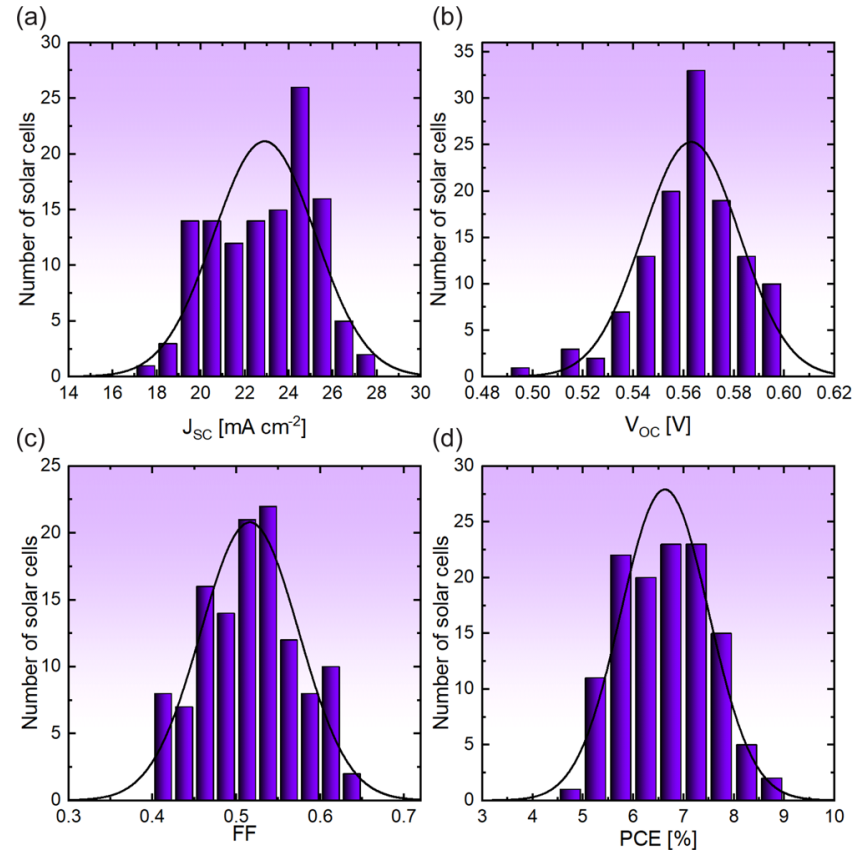

Figure 7. Device performance distributions: (a) short-circuit current density, (b) open-circuit voltage, (c) fill factor, and (d) power conversion efficiency. 
Finally, blade-coating deposition of the DFP-based PbS QD inks can be translated to industrial techniques such as R2R, which is the first step toward QD solar cell technology.

\section{EXPERIMENTAL SECTION}

PbS QD Synthesis. Lead sulfide colloidal quantum dots (PbS CQDs) capped with oleate ligands were synthesized by the hot injection method. ${ }^{55}$ As a lead precursor, $18 \mathrm{~g}$ of lead(II) oxide was used. It was mixed with $744 \mathrm{~mL}$ of octadecene (ODE) and $56 \mathrm{~mL}$ of oleic acid (OA). Then, the lead precursor solution was dried for $1 \mathrm{~h}$ under vacuum ( $1 \mathrm{mbar})$ at $140^{\circ} \mathrm{C}$ in a three-neck reaction flask using a Schlenk line. As a sulfur precursor, bis(trimethylsilyl)sulfide $\left(\mathrm{TMS}_{2} \mathrm{~S}\right)$ was used: $8.4 \mathrm{~mL}$ of $\mathrm{TMS}_{2} \mathrm{~S}$ was dissolved in $400 \mathrm{~mL}$ of dried ODE in a closed addition funnel in the nitrogen-filled glovebox. The addition funnel was attached to the flask with lead oleate solution. The reaction was carried out under a nitrogen atmosphere. The lead precursor solution was heated to $87^{\circ} \mathrm{C}$, and when the temperature reaches this point, heating was turned off and the flask was evacuated down to 5 mbar. After that, the valve of the addition funnel was opened and the sulfur precursor solution was quickly injected to the lead precursor solution. Upon complete injection, the flask was recharged with nitrogen. After $8 \mathrm{~min}$ of $\mathrm{QD}$ growth, the reaction was quenched by cooling the reaction flask down to room temperature using a cold-water bath. To isolate the nanocrystals, hexane $(0.6 \mathrm{~L})$ and ethanol $(6 \mathrm{~L})$ were added followed by centrifugation. CQD were again re-dispersed in $0.6 \mathrm{~L}$ of hexane and precipitated by $1.1 \mathrm{~L}$ of ethanol. For the third washing cycle, $0.3 \mathrm{~L}$ of hexane and $0.46 \mathrm{~L}$ of ethanol were used. Finally, PbS CQDs were redispersed in $100 \mathrm{~mL}$ of anhydrous hexane inside the glovebox. Solution concentrations were determined by the measurement of the absorption of diluted solutions at $400 \mathrm{~nm} .^{56}$

Preparation of the PbS QD Inks. The procedure for phase transfer ligand exchange was adapted from our previous work. ${ }^{43}$ Ten milliliters of oleate-capped PbS CQDs dispersed in hexanes $(\sim 5 \mathrm{mg} /$ $\mathrm{mL}$ ) was poured on top $10 \mathrm{~mL}$ of a $50 \mathrm{mM} \mathrm{MAI}: \mathrm{PbI}_{2}=1: 1$ solution in NMF. The mixture was stirred for $3 \mathrm{~h}$ followed by the phase transfer of $\mathrm{PbS} \mathrm{QDs}$ to the NMF phase. Phase separation after complete ligand exchange was quite fast (within 5-7 min). The polar phase was rinsed three times with hexane $(3 \times 10 \mathrm{~mL})$. The PbS$\mathrm{MAPbI}_{3}$ QDs were precipitated by adding $10 \mathrm{~mL}$ of acetone and immediate centrifugation at $4500 \mathrm{rpm}$ for $5 \mathrm{~min}$. The supernatant was removed, and the pellet redispersed in DFP at $170 \mathrm{mg} / \mathrm{mL}$ concentration for blade coating. Higher concentrations have been also tried $(300 \mathrm{mg} / \mathrm{mL}$ is still possible). For the spectroscopy measurements, $\mathrm{PbS}-\mathrm{MAPbI}_{3}$ inks were dispersed to the concentration of $0.5-1 \mathrm{mg} \mathrm{ml}^{-1}$.

ZnO Nanocrystal (NC) Synthesis. The method was adopted from the work of René A.J. at. all. ${ }^{45}$ Briefly, zinc acetate dihydrate (5.9 $\mathrm{g}, 26.8 \mathrm{mmol})$ was dissolved in methanol $(250 \mathrm{~mL})$ at $60^{\circ} \mathrm{C}$, and a solution of $\mathrm{KOH}(2.96 \mathrm{~g}, 26 \mathrm{mmol})$ in methanol $(130 \mathrm{~mL})$ was added in $10 \mathrm{~min}$ to the zinc acetate dihydrate solution under stirring. After 2 $\mathrm{h}$ and $15 \mathrm{~min}$, the reaction was stopped and the nanoparticles were allowed to precipitate overnight. The precipitate was washed three times with methanol $(100 \mathrm{~mL})$, and nanocrystals were stored in the fridge under a layer of $\mathrm{MeOH}$. The nanocrystals were dissolved in a mixture of $\mathrm{MeOH}: \mathrm{CHCl}_{3}=1: 1 \mathrm{v} / \mathrm{v}$ directly before the deposition to the concentration of about $65 \mathrm{mg} / \mathrm{mL}$. Characterization of the $\mathrm{ZnO}$ NCs can be found in Figure S7.

Device Fabrication. Pre-patterned glass substrates with indium tin oxide (ITO) were polished with detergent and then subsequently sonicated in water, acetone, and isopropanol and dried in an oven at $130{ }^{\circ} \mathrm{C}$ for $20 \mathrm{~min}$. Before $\mathrm{ZnO}$ deposition, the ITO substrates were treated with $\mathrm{O}_{2}$-plasma.

Deposition of ZnO Nanocrystal Films for ETL. ZnO nanocrystals were deposited from $\mathrm{MeOH}: \mathrm{CHCl}_{3}=1: 1(\mathrm{v} / \mathrm{v})$ solutions by spin coating at $3000 \mathrm{rpm}$ for $30 \mathrm{~s}$. The $\mathrm{ZnO}$ layer was annealed at $120^{\circ} \mathrm{C}$ for $20 \mathrm{~min}$ to get rid of the solvent's residuals.

PbS QD Ink Deposition. PbS QD films were fabricated in a nitrogen-filled glovebox using the blade-coating method. The ink concentration was set to $170 \mathrm{mg} \mathrm{m}^{-1}$. After the ink re-dispersing in DFP, they were filtered using a $0.2 \mu \mathrm{m}$ nylon filter. The slit of the blade was set to $200 \mu \mathrm{m}$, our standard deposition temperature of the hot plate was $100{ }^{\circ} \mathrm{C}$ (standard, but $70{ }^{\circ} \mathrm{C}$ is also enough), and the speed was $90 \mathrm{~mm} \mathrm{~s}^{-1}$. After the inks were spread over the substrate, they were annealed at $70{ }^{\circ} \mathrm{C}$ for an additional $10 \mathrm{~min}$.

Deposition of the HTL (PbS-EDT). PbS-EDT was deposited using the LbL method in a nitrogen-filled glovebox. PbS QDs capped by oleic acid ligands were spin-cast from hexane solutions $\left(5 \mathrm{mg} \mathrm{mL}^{-1}\right)$ onto the blade-coated PbS-MAPbI ${ }_{3}$ layer. Ligand exchange was performed by exposing the films to an acetonitrile solution of EDT (prepared in a concentration of $0.01 \%$ by volume) for $30 \mathrm{~s}$. Spin drying removed the residuals of the ligand solutions. To get rid of the products of ligand exchange and the excess of unreacted ligands, films were washed twice with acetonitrile. Cycles of deposition of the $\mathrm{PbS}$ QDs, ligand exchange, and washing were repeated three times to produce a $60 \mathrm{~nm}$-thick PbS-EDT layer.

Back Electrode Deposition. The devices were finalized by thermal evaporation of $80 \mathrm{~nm}$ of gold under the pressure of $1-5 \times 10^{-8} \mathrm{mbar}$ at the rate of $0.5 \AA \mathrm{s}^{-1}$. The device area defined by the overlap of FTO and $\mathrm{Au}$ electrodes is $0.16 \mathrm{~cm}^{2}$. After Au deposition, the devices were kept in air.

Current-Voltage Characterization. JV measurements were carried out in a nitrogen-filled glovebox under simulated AM1.5G solar illumination, using a Steuernagel Solar constant 1200 metal halide lamp set to $100 \mathrm{~mW} \mathrm{~cm}{ }^{-2}$ intensity and a Keithley 2400 source meter. Light was calibrated using a monocrystalline silicon solar cell (WRVS reference cell, Fraunhofer ISE) and corrected for the spectral mismatch. For efficiency calculations, the illuminated area was confined by a shadow mask $\left(0.10 \mathrm{~cm}^{2}\right)$ to avoid any edge effects. The temperature was set to $295 \mathrm{~K}$ by a flux of cold $\mathrm{N}_{2}$.

The External Quantum Efficiency Measurements. The external quantum efficiency (EQE) was measured under monochromatic light under short-circuit conditions. For the source of white light, a $250 \mathrm{~W}$ quartz tungsten halogen lamp (6334NS, Newport) with lamp housing (67009, Newport) was used. Narrow bandpass filters (Thorlabs) with a full width half maximum (FWHM) of $10 \pm 2 \mathrm{~nm}$ from 400 to $1300 \mathrm{~nm}$ and an FWHM of $12 \pm 2.4 \mathrm{~nm}$ from 1300 to $1400 \mathrm{~nm}$ had been used for monochromatic light. The light intensity is determined by calibrated PD300 and PD300IR photodiodes (Ophir Optics) for the visible and infrared parts of the spectrum, respectively.

Spectroscopic Characterization. The absorbance spectra were collected using a Shimadzu UV-3000 UV/vis/near-infrared (NIR) spectrometer. For the steady-state photoluminescence (PL) measurements, the second harmonic ( $3.1 \mathrm{eV})$ from a mode-locked Ti:sapphire laser (Mira 900, Coherent) was used as an excitation source. The laser power was adjusted using neutral-density filters to $0.3 \mathrm{~mW}$ (solutions) or $3 \mathrm{~mW}$ (thin films). The excitation beam was spatially limited by an iris and focused with a $150 \mathrm{~mm}$ focal length lens. The PL was collected into a spectrometer and recorded using an Andor $1.7 \mu \mathrm{m}$ InGaAs camera.

FTIR. The measurements were performed using a Shimadzu IRTracer-100 in transmission mode. Samples were prepared by grinding of the solids (around $1 \%$ by mass) with $\mathrm{KBr}$ powder and formation of transparent pellets by the hydraulic press.

X-ray Powder Diffraction. The X-ray diffraction data were collected using a Bruker D8 Advanced diffractometer operating with a $\mathrm{Cu} \mathrm{K} \mathrm{K}_{\alpha}$ radiation source $(\lambda=1.54 \AA)$ and Lynxeye detector under ambient conditions.

${ }^{1} \mathrm{H}$ NMR. Proton nuclear magnetic resonance spectra were recorded on a Varian VXR400 $(400 \mathrm{MHz})$ spectrometer equipped with a $5 \mathrm{~mm}$ z-gradient broadband probe, using $\mathrm{CDCl}_{3}$ as a solvent. Chemical shifts $(\delta)$ are reported in ppm relative to the residual solvent peak $\left(\delta=7.26 \mathrm{ppm}\right.$ for $\left.\mathrm{CDCl}_{3}\right)$.

Morphological Characterization. AFM measurements were obtained under ambient conditions. The AFM images were taken with a Bruker microscope (MultiMode 8 with ScanAsyst) in ScanAsyst Peak Force Tapping mode with SCANASYST-AIR probes having an elastic constant $k=0.4 \mathrm{~N} \mathrm{~m}^{-1}$, a resonance frequency of 70 $\mathrm{kHz}$, and a tip radius less than $12 \mathrm{~nm}$ (nominal $2 \mathrm{~nm}$ ). The images 
were taken with a scan rate of $0.98 \mathrm{~Hz}$ and the resolution of 1024 lines/sample.

Thickness Measurements. The thicknesses of the PbS CQD films and $\mathrm{ZnO}$ layers were measured by a profilometer (Dektak 6M Stylus Profiler Veeco).

TEM Analysis. The preparation of TEM cross-sectional specimen was done with a FEI Helios G4 CX focused ion beam (FIB), using gradually decreasing acceleration voltages of 30,5 , and $2 \mathrm{kV}$ to remove the high-energy preparation damage. TEM analyses were performed with a double aberration corrected FEI Themis Z, operated at $300 \mathrm{kV}$. High-angle annular dark-field (HAADF)-STEM images were recorded with a probe current of approx. $200 \mathrm{pA}$, convergence semi-angle $21 \mathrm{mrad}$, and HAADF collection angles 61200 mrad. EDX spectrum imaging was performed with a probe current of approx. $1 \mathrm{nA}$, where the spectra were recorded with a Dual$\mathrm{X}$ system, providing in total $1.76 \mathrm{sr}$ EDX detectors.

\section{ASSOCIATED CONTENT}

\section{(s) Supporting Information}

The Supporting Information is available free of charge at https://pubs.acs.org/doi/10.1021/acsami.0c18204.

Assignment of the FTIR signals, ${ }^{1} \mathrm{H}$ NMR spectra, some of the solvent constants, additional HRTEM images, XRD powder diffractograms, photographs of the bladecoated films, EDS measurements of the solar cell's cross section, and characterization of $\mathrm{ZnO}$ nanocrystals (PDF)

\section{AUTHOR INFORMATION}

\section{Corresponding Author}

Maria A. Loi - Zernike Institute for Advanced Materials, Groningen 9747 AG, The Netherlands; (1) orcid.org/00000002-7985-7431; Email: m.a.loi@rug.nl

\section{Authors}

Nataliia Sukharevska - Zernike Institute for Advanced Materials, Groningen 9747 AG, The Netherlands

Dmytro Bederak - Zernike Institute for Advanced Materials, Groningen 9747 AG, The Netherlands

Vincent M. Goossens - Zernike Institute for Advanced Materials, Groningen 9747 AG, The Netherlands

Jamo Momand - Zernike Institute for Advanced Materials, Groningen 9747 AG, The Netherlands

Herman Duim - Zernike Institute for Advanced Materials, Groningen 9747 AG, The Netherlands

Dmitry N. Dirin - Department of Chemistry and Applied Biosciences, ETH Zurich, Zurich 8093, Switzerland; EMPASwiss Federal Laboratories for Materials Science and Technology, Dubendorf 8600, Switzerland; 이이.org/ 0000-0002-5187-4555

Maksym V. Kovalenko - Department of Chemistry and Applied Biosciences, ETH Zurich, Zurich 8093, Switzerland; EMPA-Swiss Federal Laboratories for Materials Science and Technology, Dubendorf 8600, Switzerland; 이이.org/ 0000-0002-6396-8938

Bart J. Kooi - Zernike Institute for Advanced Materials, Groningen 9747 AG, The Netherlands

Complete contact information is available at: https://pubs.acs.org/10.1021/acsami.0c18204

\section{Notes}

The authors declare no competing financial interest.

\section{ACKNOWLEDGMENTS}

N.V.S. and M.A.L. acknowledge the financial support of the ERC Starting Grant "Hybrids Solution Processable Optoelectronic Devices” (Hy-SPOD) (ERC306983). Gert ten Brink is acknowledged for assistance with TEM image processing, and Jacob Baas is acknowledged for help with XRD measurements. Teodor Zaharia and Arjen Kamp are acknowledged for technical support. The authors are thankful to Lorenzo Di Mario for discussions on the spectroscopy experiments.

\section{REFERENCES}

(1) Litvin, A. P.; Martynenko, I. V.; Purcell-Milton, F.; Baranov, A. V.; Fedorov, A. V.; Gun'ko, Y. K. Colloidal Quantum Dots for Optoelectronics. J. Mater. Chem. A 2017, 5, 13252-13275.

(2) Kovalenko, M. V.; Manna, L.; Cabot, A.; Hens, Z.; Talapin, D. V.; Kagan, C. R.; Klimov, V. I.; Rogach, A. L.; Reiss, P.; Milliron, D. J.; Guyot-Sionnnest, P.; Konstantatos, G.; Parak, W. J.; Hyeon, T.; Korgel, B. A.; Murray, C. B.; Heiss, W. Prospects of Nanoscience with Nanocrystals. ACS Nano 2015, 9, 1012-1057.

(3) Bederak, D.; Balazs, D. M.; Sukharevska, N. V.; Shulga, A. G.; Abdu-Aguye, M.; Dirin, D. N.; Kovalenko, M. V.; Loi, M. A. Comparing Halide Ligands in PbS Colloidal Quantum Dots for FieldEffect Transistors and Solar Cells. ACS Appl. Nano Mater. 2018, 1, 6882-6889.

(4) Balazs, D. M.; Dirin, D. N.; Fang, H. H.; Protesescu, L.; Ten Brink, G. H.; Kooi, B. J.; Kovalenko, M. V.; Loi, M. A. CounterionMediated Ligand Exchange for $\mathrm{PbS}$ Colloidal Quantum Dot Superlattices. ACS Nano 2015, 9, 11951-11959.

(5) Shulga, A. G.; Piveteau, L.; Bisri, S. Z.; Kovalenko, M. V.; Loi, M. A. Double Gate PbS Quantum Dot Field-Effect Transistors for Tuneable Electrical Characteristics. Adv. Electron. Mater. 2016, 2, 1500467.

(6) Yang, Z.; Voznyy, O.; Liu, M.; Yuan, M.; Ip, A. H.; Ahmed, O. S.; Levina, L.; Kinge, S.; Hoogland, S.; Sargent, E. H. All-QuantumDot Infrared Light-Emitting Diodes. ACS Nano 2015, 9, 1232712333.

(7) Sun, L.; Choi, J. J.; Stachnik, D.; Bartnik, A. C.; Hyun, B.-R.; Malliaras, G. G.; Hanrath, T.; Wise, F. W. Bright Infrared QuantumDot Light-Emitting Diodes through Inter-Dot Spacing Control. Nat. Nanotechnol. 2012, 7, 369-373.

(8) Shulga, A. G.; Kahmann, S.; Dirin, D. N.; Graf, A.; Zaumseil, J.; Kovalenko, M. V.; Loi, M. A. Electroluminescence Generation in PbS Quantum Dot Light-Emitting Field-Effect Transistors with Solid-State Gating. ACS Nano 2018, 12, 12805-12813.

(9) Shulga, A. G.; Derenskyi, V.; Salazar-Rios, J. M.; Dirin, D. N.; Fritsch, M.; Kovalenko, M. V.; Scherf, U.; Loi, M. A. An All-SolutionBased Hybrid CMOS-Like Quantum Dot/Carbon Nanotube Inverter. Adv. Mater. 2017, 29, 1701764.

(10) Sytnyk, M.; Yakunin, S.; Schöfberger, W.; Lechner, R. T.; Burian, M.; Ludescher, L.; Killilea, N. A.; YousefiAmin, A.; Kriegner, D.; Stangl, J.; Groiss, H.; Heiss, W. Quasi-Epitaxial Metal-Halide Perovskite Ligand Shells on PbS Nanocrystals. ACS Nano 2017, 11, $1246-1256$.

(11) McDonald, S. A.; Konstantatos, G.; Zhang, S.; Cyr, P. W.; Klem, E. J. D.; Levina, L.; Sargent, E. H. Solution-Processed PbS Quantum Dot Infrared Photodetectors and Photovoltaics. Nat. Mater. 2005, 4, 138-142.

(12) Tang, H.; Zhong, J.; Chen, W.; Shi, K.; Mei, G.; Zhang, Y.; Wen, Z.; Müller-Buschbaum, P.; Wu, D.; Wang, K.; Sun, X. W. Lead Sulfide Quantum Dot Photodetector with Enhanced Responsivity through a Two-Step Ligand-Exchange Method. ACS Appl. Nano Mater. 2019, 2, 6135-6143.

(13) Choi, M.-J.; García de Arquer, F. P.; Proppe, A. H.; Seifitokaldani, A.; Choi, J.; Kim, J.; Baek, S.-W.; Liu, M.; Sun, B.; Biondi, M.; Scheffel, B.; Walters, G.; Nam, D.-H.; Jo, J. W.; Ouellette, O.; Voznyy, O.; Hoogland, S.; Kelley, S. O.; Jung, Y. S.; Sargent, E. H. Cascade Surface Modification of Colloidal Quantum Dot Inks 
Enables Efficient Bulk Homojunction Photovoltaics. Nat. Commun. 2020, 11, 103.

(14) Xu, J.; Voznyy, O.; Liu, M.; Kirmani, A. R.; Walters, G.; Munir, R.; Abdelsamie, M.; Proppe, A. H.; Sarkar, A.; García de Arquer, F. P.; Wei, M.; Sun, B.; Liu, M.; Ouellette, O.; Quintero-Bermudez, R.; Li, J.; Fan, J.; Quan, L.; Todorovic, P.; Tan, H.; Hoogland, S.; Kelley, S. O.; Stefik, M.; Amassian, A.; Sargent, E. H. 2D Matrix Engineering for Homogeneous Quantum Dot Coupling in Photovoltaic Solids. Nat. Nanotechnol. 2018, 13, 456-462.

(15) Liu, M.; Voznyy, O.; Sabatini, R.; García de Arquer, F. P.; Munir, R.; Balawi, A. H.; Lan, X.; Fan, F.; Walters, G.; Kirmani, A. R.; Hoogland, S.; Laquai, F.; Amassian, A.; Sargent, E. H. Hybrid Organic-Inorganic Inks Flatten the Energy Landscape in Colloidal Quantum Dot Solids. Nat. Mater. 2017, 16, 258-263.

(16) Yang, Z.; Janmohamed, A.; Lan, X.; García de Arquer, F. P.; Voznyy, O.; Yassitepe, E.; Kim, G.-H.; Ning, Z.; Gong, X.; Comin, R.; Sargent, E. H. Colloidal Quantum Dot Photovoltaics Enhanced by Perovskite Shelling. Nano Lett. 2015, 15, 7539-7543.

(17) Kovalenko, M. V. Opportunities and Challenges for Quantum Dot Photovoltaics. Nat. Nanotechnol. 2015, 10, 994-997.

(18) Giansante, C.; Infante, I.; Fabiano, E.; Grisorio, R.; Suranna, G. P.; Gigli, G. "Darker-than-Black" PbS Quantum Dots: Enhancing Optical Absorption of Colloidal Semiconductor Nanocrystals via Short Conjugated Ligands. J. Am. Chem. Soc. 2015, 137, 1875-1886.

(19) Ellingson, R. J.; Beard, M. C.; Johnson, J. C.; Yu, P.; Micic, O. I.; Nozik, A. J.; Shabaev, A.; Efros, A. L. Highly Efficient Multiple Exciton Generation in Colloidal $\mathrm{PbSe}$ and $\mathrm{PbS}$ Quantum Dots. Nano Lett. 2005, 5, 865-871.

(20) Wang, L.; Wang, Y.; Jia, Y.; Liu, X.; Liu, T.; Fu, T.; Li, J.; Weng, B.; Zhang, X.; Liu, Y. Manipulation of Phase-Transfer LigandExchange Dynamics of PbS Quantum Dots for Efficient Infrared Photovoltaics. J. Phys. Chem. C 2019, 123, 30137-30144.

(21) Fan, J. Z.; Vafaie, M.; Bertens, K.; Sytnyk, M.; Pina, J. M.; Sagar, L. K.; Ouellette, O.; Proppe, A. H.; Rasouli, A. S.; Gao, Y.; Baek, S.-W.; Chen, B.; Laquai, F.; Hoogland, S.; Arquer, F. P. G. .; Heiss, W.; Sargent, E. H. Micron Thick Colloidal Quantum Dot Solids. Nano Lett. 2020, 20, 5284-5291.

(22) Wang, Y.; Liu, Z.; Huo, N.; Li, F.; Gu, M.; Ling, X.; Zhang, Y.; Lu, K.; Han, L.; Fang, H.; Shulga, A. G.; Xue, Y.; Zhou, S.; Yang, F.; Tang, X.; Zheng, J.; Antonietta Loi, M.; Konstantatos, G.; Ma, W. Room-Temperature Direct Synthesis of Semi-Conductive $\mathrm{PbS}$ Nanocrystal Inks for Optoelectronic Applications. Nat. Commun. 2019, 10, 5136.

(23) Speirs, M. J.; Dirin, D. N.; Abdu-Aguye, M.; Balazs, D. M.; Kovalenko, M. V.; Loi, M. A. Temperature Dependent Behaviour of Lead Sulfide Quantum Dot Solar Cells and Films. Energy Environ. Sci. 2016, 9, 2916-2924.

(24) Yang, Z.; Fan, J. Z.; Proppe, A. H.; de Arquer, F. P. G.; Rossouw, D.; Voznyy, O.; Lan, X.; Liu, M.; Walters, G.; QuinteroBermudez, R.; Sun, B.; Hoogland, S.; Botton, G. A.; Kelley, S. O.; Sargent, E. H. Mixed-Quantum-Dot Solar Cells. Nat. Commun. 2017, 8,1325 .

(25) Sukharevska, N.; Bederak, D.; Dirin, D.; Kovalenko, M.; Loi, M. A. Improved Reproducibility of PbS Colloidal Quantum Dots Solar Cells Using Atomic Layer-Deposited $\mathrm{TiO}_{2}$. Energy Technol. 2020, 8, 1900887.

(26) Chuang, C.-H. M.; Brown, P. R.; Bulović, V.; Bawendi, M. G. Improved Performance and Stability in Quantum Dot Solar Cells through Band Alignment Engineering. Nat. Mater. 2014, 13, 796801.

(27) Gu, M.; Wang, Y.; Yang, F.; Lu, K.; Xue, Y.; Wu, T.; Fang, H.; Zhou, S.; Zhang, Y.; Ling, X.; Xu, Y.; Li, F.; Yuan, J.; Loi, M. A.; Liu, Z.; Ma, W. Stable PbS Quantum Dot Ink for Efficient Solar Cells by Solution-Phase Ligand Engineering. J. Mater. Chem. A 2019, 7, 15951-15959.

(28) Cao, Y.; Stavrinadis, A.; Lasanta, T.; So, D.; Konstantatos, G. The Role of Surface Passivation for Efficient and Photostable PbS Quantum Dot Solar Cells. Nat. Energy 2016, 1, 16035.
(29) Salazar-Rios, J. M.; Sukharevska, N.; Speirs, M. J.; Jung, S.; Dirin, D.; Dragoman, R. M.; Allard, S.; Kovalenko, M. V.; Scherf, U.; Loi, M. A. Enhancing Quantum Dot Solar Cells Stability with a Semiconducting Single-Walled Carbon Nanotubes Interlayer Below the Top Anode. Adv. Mater. Interfaces 2018, 5, 1801155.

(30) Kirmani, A. R.; Luther, J. M.; Abolhasani, M.; Amassian, A. Colloidal Quantum Dot Photovoltaics: Current Progress and Path to Gigawatt Scale Enabled by Smart Manufacturing. ACS Energy Lett. 2020, 5, 3069-3100.

(31) Lin, Q.; Yun, H. J.; Liu, W.; Song, H.-J.; Makarov, N. S.; Isaienko, O.; Nakotte, T.; Chen, G.; Luo, H.; Klimov, V. I.; Pietryga, J. M. Phase-Transfer Ligand Exchange of Lead Chalcogenide Quantum Dots for Direct Deposition of Thick, Highly Conductive Films. J. Am. Chem. Soc. 2017, 139, 6644-6653.

(32) Zhitomirsky, D.; Voznyy, O.; Levina, L.; Hoogland, S.; Kemp, K. W.; Ip, A. H.; Thon, S. M.; Sargent, E. H. Engineering Colloidal Quantum Dot Solids within and beyond the Mobility-Invariant Regime. Nat. Commun. 2014, 5, 3803.

(33) Peng, J.; Chen, Y.; Zhang, X.; Dong, A.; Liang, Z. Solid-State Ligand-Exchange Fabrication of $\mathrm{CH}_{3} \mathrm{NH}_{3} \mathrm{PbI}_{3}$ Capped $\mathrm{PbS}$ Quantum Dot Solar Cells. Adv. Sci. 2016, 3, 1500432.

(34) Ip, A. H.; Thon, S. M.; Hoogland, S.; Voznyy, O.; Zhitomirsky, D.; Debnath, R.; Levina, L.; Rollny, L. R.; Carey, G. H.; Fischer, A.; Kemp, K. W.; Kramer, I. J.; Ning, Z.; Labelle, A. J.; Chou, K. W.; Amassian, A.; Sargent, E. H. Hybrid Passivated Colloidal Quantum Dot Solids. Nat. Nanotechnol. 2012, 7, 577-582.

(35) Choi, H.; Lee, J.-G.; Mai, X. D.; Beard, M. C.; Yoon, S. S.; Jeong, S. Supersonically Spray-Coated Colloidal Quantum Dot Ink Solar Cells. Sci. Rep. 2017, 7, 622.

(36) Dirin, D. N.; Dreyfuss, S.; Bodnarchuk, M. I.; Nedelcu, G.; Papagiorgis, P.; Itskos, G.; Kovalenko, M. V. Lead Halide Perovskites and Other Metal Halide Complexes As Inorganic Capping Ligands for Colloidal Nanocrystals. J. Am. Chem. Soc. 2014, 136, 6550-6553.

(37) Kovalenko, M. V.; Scheele, M.; Talapin, D. V. Colloidal Nanocrystals with Molecular Metal Chalcogenide Surface Ligands. Science 2009, 324, 1417-1420.

(38) Zhang, X.; Zhang, J.; Phuyal, D.; Du, J.; Tian, L.; Öberg, V. A.; Johansson, M. B.; Cappel, U. B.; Karis, O.; Liu, J.; Rensmo, H.; Boschloo, G.; Johansson, E. M. J. Inorganic $\mathrm{CsPbI}_{3}$ Perovskite Coating on PbS Quantum Dot for Highly Efficient and Stable Infrared Light Converting Solar Cells. Adv. Energy Mater. 2018, 8, 1702049.

(39) Albaladejo-Siguan, M.; Becker-Koch, D.; Taylor, A. D.; Sun, Q.; Lami, V.; Oppenheimer, P. G.; Paulus, F.; Vaynzof, Y. Efficient and Stable PbS Quantum Dot Solar Cells by Triple-Cation Perovskite Passivation. ACS Nano 2020, 14, 384-393.

(40) Jia, D.; Chen, J.; Zheng, S.; Phuyal, D.; Yu, M.; Tian, L.; Liu, J.; Karis, O.; Rensmo, H.; Johansson, E. M. J.; Zhang, X. Highly Stabilized Quantum Dot Ink for Efficient Infrared Light Absorbing Solar Cells. Adv. Energy Mater. 2019, 9, 1902809.

(41) Liu, M.; Che, F.; Sun, B.; Voznyy, O.; Proppe, A.; Munir, R.; Wei, M.; Quintero-Bermudez, R.; Hu, L.; Hoogland, S.; Mandelis, A.; Amassian, A.; Kelley, S. O.; García de Arquer, F. P.; Sargent, E. H. Controlled Steric Hindrance Enables Efficient Ligand Exchange for Stable, Infrared-Bandgap Quantum Dot Inks. ACS Energy Lett. 2019, 4, 1225-1230.

(42) Beygi, H.; Sajjadi, S. A.; Babakhani, A.; Young, J. F.; van Veggel, F. C. J. M. Surface Chemistry of As-Synthesized and Air-Oxidized PbS Quantum Dots. Appl. Surf. Sci. 2018, 457, 1-10.

(43) Xia, Y.; Chen, W.; Zhang, P.; Liu, S.; Wang, K.; Yang, X.; Tang, H.; Lian, L.; He, J.; Liu, X.; Liang, G.; Tan, M.; Gao, L.; Liu, H.; Song, H.; Zhang, D.; Gao, J.; Wang, K.; Lan, X.; Zhang, X.; MüllerBuschbaum, P.; Tang, J.; Zhang, J. Facet Control for Trap-State Suppression in Colloidal Quantum Dot Solids. Adv. Funct. Mater. 2020, 30, 2000594

(44) Crisp, R. W.; Kroupa, D. M.; Marshall, A. R.; Miller, E. M.; Zhang, J.; Beard, M. C.; Luther, J. M. Metal Halide Solid-State Surface Treatment for High Efficiency PbS and PbSe QD Solar Cells. Sci. Rep. 2015, 5, 9945. 
(45) Beek, W. J. E.; Wienk, M. M.; Kemerink, M.; Yang, X.; Janssen, R. A. J. Hybrid Zinc Oxide Conjugated Polymer Bulk Heterojunction Solar Cells. J. Phys. Chem. B 2005, 109, 9505-9516.

(46) Kirmani, A. R.; Sheikh, A. D.; Niazi, M. R.; Haque, M. A.; Liu, M.; de Arquer, F. P. G.; Xu, J.; Sun, B.; Voznyy, O.; Gasparini, N.; Baran, D.; Wu, T.; Sargent, E. H.; Amassian, A. Overcoming the Ambient Manufacturability-Scalability-Performance Bottleneck in Colloidal Quantum Dot Photovoltaics. Adv. Mater. 2018, 30, 1801661.

(47) Bederak, D.; Sukharevska, N.; Kahmann, S.; Abdu-Aguye, M.; Duim, H.; Dirin, D. N.; Kovalenko, M. V.; Portale, G.; Loi, M. A. On the Colloidal Stability of $\mathrm{PbS}$ Quantum Dots Capped with Methylammonium Lead Iodide Ligands. ACS Appl. Mater. Interfaces 2020, 12, 52959-52966.

(48) Balazs, D. M.; Rizkia, N.; Fang, H.-H.; Dirin, D. N.; Momand, J.; Kooi, B. J.; Kovalenko, M. V.; Loi, M. A. Colloidal Quantum Dot Inks for Single-Step-Fabricated Field-Effect Transistors: The Importance of Postdeposition Ligand Removal. ACS Appl. Mater. Interfaces 2018, 10, 5626-5632.

(49) Zherebetskyy, D.; Scheele, M.; Zhang, Y.; Bronstein, N.; Thompson, C.; Britt, D.; Salmeron, M.; Alivisatos, P.; Wang, L.-W. Hydroxylation of the Surface of $\mathrm{PbS}$ Nanocrystals Passivated with Oleic Acid. Science 2014, 344, 1380-1384.

(50) Boles, M. A.; Ling, D.; Hyeon, T.; Talapin, D. V. The Surface Science of Nanocrystals. Nat. Mater. 2016, 15, 141-153.

(51) Cass, L. C.; Malicki, M.; Weiss, E. A. The Chemical Environments of Oleate Species within Samples of Oleate-Coated PbS Quantum Dots. Anal. Chem. 2013, 85, 6974-6979.

(52) Sliz, R.; Lejay, M.; Fan, J. Z.; Choi, M.-J.; Kinge, S.; Hoogland, S.; Fabritius, T.; García de Arquer, F. P.; Sargent, E. H. Stable Colloidal Quantum Dot Inks Enable Inkjet-Printed High-Sensitivity Infrared Photodetectors. ACS Nano 2019, 13, 11988-11995.

(53) Clifford, J. P.; Konstantatos, G.; Johnston, K. W.; Hoogland, S.; Levina, L.; Sargent, E. H. Fast, Sensitive and Spectrally Tuneable Colloidal-Quantum-Dot Photodetectors. Nat. Nanotechnol. 2009, 4, $40-44$.

(54) Shulga, A. G.; Yamamura, A.; Tsuzuku, K.; Dragoman, R. M.; Dirin, D. N.; Watanabe, S.; Kovalenko, M. V.; Takeya, J.; Loi, M. A. Patterned Quantum Dot Photosensitive FETs for Medium Frequency Optoelectronics. Adv. Mater. Technol. 2019, 4, 1900054.

(55) Yarema, M.; Yarema, O.; Lin, W. M. M.; Volk, S.; Yazdani, N.; Bozyigit, D.; Wood, V. Upscaling Colloidal Nanocrystal Hot-Injection Syntheses via Reactor Underpressure. Chem. Mater. 2017, 29, 796803.

(56) Moreels, I.; Lambert, K.; Smeets, D.; De Muynck, D.; Nollet, T.; Martins, J. C.; Vanhaecke, F.; Vantomme, A.; Delerue, C.; Allan, G.; Hens, Z. Size-Dependent Optical Properties of Colloidal PbS Quantum Dots. ACS Nano 2009, 3, 3023-3030. 